University of Nebraska - Lincoln

DigitalCommons@University of Nebraska - Lincoln

Faculty Publications: Department of Teaching, Department of Teaching, Learning and Teacher Learning and Teacher Education

Education

2-2013

\title{
Associations Between Teacher Emotional Support and Depressive Symptoms in Australian Adolescents: A 5-Year Longitudinal Study
}

\author{
Patrick Pössel \\ University of Louisville, patrick.possel@louisville.edu \\ Kathleen Moritz Rudasill \\ University of Nebraska-Lincoln, kmrudasill@vcu.edu \\ Michael G. Sawyer \\ University of Adelaide, Australia, michael.sawyer@adelaide.edu.au \\ Susan H. Spence \\ Griffith University, Queensland, Australia, s.spence@griffith.edu.au \\ Annie C. Bjerg \\ University of Louisville
}

Follow this and additional works at: https://digitalcommons.unl.edu/teachlearnfacpub

Part of the Curriculum and Instruction Commons, and the Teacher Education and Professional

Development Commons

Pössel, Patrick; Rudasill, Kathleen Moritz; Sawyer, Michael G.; Spence, Susan H.; and Bjerg, Annie C., "Associations Between Teacher Emotional Support and Depressive Symptoms in Australian Adolescents: A 5-Year Longitudinal Study" (2013). Faculty Publications: Department of Teaching, Learning and Teacher Education. 137.

https://digitalcommons.unl.edu/teachlearnfacpub/137

This Article is brought to you for free and open access by the Department of Teaching, Learning and Teacher Education at DigitalCommons@University of Nebraska - Lincoln. It has been accepted for inclusion in Faculty Publications: Department of Teaching, Learning and Teacher Education by an authorized administrator of DigitalCommons@University of Nebraska - Lincoln. 


\title{
Associations Between Teacher Emotional Support and Depressive Symptoms in Australian Adolescents: A 5-Year Longitudinal Study
}

\author{
Patrick Pössel, ${ }^{1}$ Kathleen Moritz Rudasill, ${ }^{2}$ Michael G. Sawyer, ${ }^{3}$ \\ Susan H. Spence, ${ }^{4}$ and Annie C. Bjerg ${ }^{1}$ \\ 1. Department of Educational and Counseling Psychology, University of Louisville \\ 2. Department of Educational Psychology, University of Nebraska-Lincoln \\ 3. Discipline of Paediatrics, University of Adelaide, Adelaide, South Australia, Australia, and \\ Evaluation Unit, Women's and Children's Hospital, North Adelaide, South Australia, Australia \\ 4. Griffith University, Nathan, Queensland, Australia
}

Corresponding author - Patrick Pössel, Department of Educational and Counseling Psychology, University of Louisville, 2301 South Third Street, Louisville, KY 40292; email patrick.possel@louisville.edu

\begin{abstract}
Approximately $1 / 5$ of adolescents develop depressive symptoms. Given that youths spend a good deal of their lives at school, it seems plausible that supportive relationships with teachers could benefit their emotional well-being. Thus, the purpose of this study is to examine the association between emotionally supportive teacher relationships and depression in adolescence. The so-called principle-effect and stress-buffer models could explain relationships between teacher emotional support and depressive symptoms, yet no study has used both models to test bidirectional relationships between teacher support and depressive symptoms in students separately by sex. Four-thousand three-hundred forty-one students (boys: $n=2,063$; girls: $n=2,278$ ) from Grades 8 to 12 completed the Center for Epidemiological Studies Depression Scale (CES-D), List of Threatening Experiences Questionnaire (LTEQ), and an instrument developed for the study to measure teacher support annually for 5 years. Results support neither of the 2 proposed models. Instead, they indicate that in the 1st years of high school, students of both sexes with average and high numbers of stressful events benefit from teacher support, while teacher support might have iatrogenic effects on students experiencing low numbers of stressful events. Possible explanations for the findings and future research are discussed.
\end{abstract}

Keywords: teacher support, supportive relationships, depression, high school students

Previous research has shown that approximately $20 \%$ of girls and $7 \%$ of boys develop depressive symptoms before the end of their adolescent years (Angold, Erkanli, Silberg, Eaves, \& Costello, 2002; Twenge \& Nolen-Hoeksema, 2002), and the consequences of developing such symptoms may persist years later (Dunn \& Goodyer, 2006). Given the prevalence and consequences of depression, it is important to identify potential opportunities for prevention and early intervention.

A large body of work pointing to the positive impact of supportive relationships on depression in adolescents (for a review see Rudolph, Flynn, \& Abaied, 2008) has resulted in the development of interventions designed to reduce depressive symptoms by improving supportive relationships in schools (Sawyer et al., 2010) and student social skills (Pössel, Adelson, \& Hautzinger, 2011; Pössel, Seemann, \& Hautzinger, 2008). However, not all studies' findings clearly support the notion that supportive relationships ameliorate depression. For example, with middle school students, combined social support by classmates, friends, parents, and teachers mediated the associations between some cognitive risk factors (e.g., rumination; Abela, Vanderbilt, \& Rochon, 2004) and depression, but not others (dysfunctional attitudes; Abela \& Sullivan, 2003). Those findings raise the question of how it is possible that some studies' results show a clear positive impact of supportive relationships on depression in adolescents while others show only limited evidence of such positive impact. As Rueger, Malecki, and Demaray (2008) suggested, possible explanations include different sources (i.e., classmates, friends, parents, teachers) and different types of social support (i.e., academic, appraisal, emotional, instrumental, informational; Malecki \& Demaray, 2002). For example, social support is a multidimensional concept, and different conceptualizations 
might impact depression in different ways. This hypothesis is supported by research demonstrating that perceptions of support from one source, but not another, may affect depressive symptoms (e.g., Rueger et al., 2008). Indeed, accumulated research suggests that social support is important for the development of depressive symptoms, particularly in adolescence. At the same time, social support comes in varied forms, some of which seem to be more important than others in preventing depressive symptoms. Thus, it is helpful to identify the extent to which one source of social support (i.e., teachers) and one form of social support (i.e., emotional) are connected to depression.

Burgeoning evidence indicates that supportive relationships with parents and peers are protective against depression (e.g., Desjardins \& Leadbeater, 2011; Kerr, Preuss, \& King, 2006; Murberg \& Bru, 2004; Rueger, Malecki, \& Demaray, 2010; Stice, Ragan, \& Randall, 2004; Yang et al., 2010; Young, Berenson, Cohen, \& Garcia, 2005; Ystgaard, Tambs, \& Dalgard, 1999). However, there is limited research on associations between adolescents' supportive relationships with teachers and depression. This is surprising given that young people spend a good deal of their lives at school. It seems plausible that supportive relationships with teachers could benefit students' emotional well-being. Thus, the purpose of this study is to examine the association between emotionally supportive teacher relationships and depression in adolescence.

\section{Models of the Associations Between Supportive Relationships and Depression}

Two theoretical models have been used to investigate the relationship between depressive symptoms and social support (Dumont \& Provost, 1999). The principle-effect model (Dumont \& Provost, 1999), also known as the main- or direct-effect model (S. Cohen \& Wills, 1985), proposes that supportive relationships provide individuals with regular positive experiences and stable, socially rewarding roles that promote positive outcomes (S. Cohen \& Wills, 1985). In other words, supportive relationships can prevent depression because they give an individual the feeling of being accepted and valued by others, and this feeling, in turn, bolsters self-esteem, confidence, and efficacy, all of which are known protective factors for depression (Stice et al., 2004). There is some support for the main effect of supportive relationships on depressive symptoms in adolescents. For example, Kerr et al. (2006) found that family support was negatively associated with depressive symptoms in suicidal female adolescents during psychiatric hospitalization. Further, a 2-year longitudinal study demonstrated that deficits in parental support predict an increase in depressive symptoms (Stice et al., 2004). Thus, one might expect that the principle-effect model explains the association between supportive relationships with teachers and depressive symptoms best. If this is the case, support by teachers has the potential to benefit students regardless of the extent to which they experience stressful life events. In other words, supportive relationships with teachers could be effective mechanisms to prevent depression in universal prevention programs.

The stress-buffer model proposes that (a) stressful events increase the likelihood that an individual will develop depressive symptoms and (b) supportive relationships moderate the impact of stressful events on depressive symptoms. Contrary to the principle-effect model that predicts social support has a positive effect on individuals independent of their life situations, the stress-buffer model proposes that supportive relationships only have a positive impact when an individual faces stressful events. Indeed, there is some support for this model. For example, Murberg and Bru (2004) found parental support moderated the association between stress in form of negative life events and depressive symptoms in adolescent girls. Further, a study by Desjardins and Leadbeater (2011) revealed that emotional support from fathers reduced the association between adolescents' relational victimization and depressive symptoms. Finally, an 18-month longitudinal study demonstrated that the harmful effects of negative life events were reduced by parental support (Ystgaard et al., 1999). Hammen (2005) pointed out that multiple models explaining the development and maintenance of depression, such as the cognitive stress-vulnerability model of depression (Beck, 1976) and the self-esteem vulnerability model (Brown \& Harris, 1978), are conceptualized similarly to the stress-buffer model. Thus, these models provide further contexts to test the stressbuffer model. Findings from tests of either of the two models have generally shown support for the predicted stress-buffer effect (e.g., Harris et al., 2000; Lewinsohn, Joiner, \& Rohde, 2001).

In general, supportive relationships can play a role at two different points in the chain linking stress to depression. First, supportive relationships may interrupt associations between stressful events and stress reactions by changing individuals' perceptions of the level of stress posed by perceived challenging situations. These changed perceptions may facilitate the use of adaptive coping strategies (S. Cohen \& McKay, 1984; Cutrona \& Troutman, 1986). In other words, an individual's perception that others can and will provide necessary resources may help an individual to redefine the potential for harm posed by a stressful event and/or bolster the individual's ability to manage challenging situations. Second, supportive relationships may reduce or eliminate stress reactions, potentially by reducing the impact of stress appraisal by providing a solution for a problem and/or by reducing the perceived importance of the problem (S. Cohen \& Wills, 1985). If the stress-buffer model explains the association between supportive relationships with teachers and depressive symptoms best, support from teachers will particularly benefit students experiencing stressful life events.

Problematic social functioning is one of the core symptoms of depression (American Psychiatric Association [APA], 2000). For example, individuals with depression often withdraw from social interactions (Lewinsohn, Hoberman, Teri, \& Hautzinger, 1985). When they do not withdraw, depressed individuals continuously demand reassurance from others to substantiate their sense of self-worth and verify that others care about them (Joiner \& Metalsky, 2001). This continuous demand may cause others to avoid interacting with them. Thus, it becomes clear that not only do supportive relationships affect depressive symptoms but depression is capable of affecting supportive relationships, and bidirectional associations between both constructs should be examined.

As outlined above, several explanations for the buffering effect of supportive relationships have been proposed (S. Cohen \& McKay, 1984; S. Cohen \& Wills, 1985; Cutrona \& Troutman, 1986). These models are supported by empirical studies showing that (a) a lack of supportive relationships with parents and peers predicts an increase of depressive symptoms in 
adolescents (e.g., Young et al., 2005), and (b) depressive symptoms predict weaker quality and less stable peer relationships, especially in adolescent girls (Prinstein, Borelli, Cheah, Simon, \& Aikins, 2005; Stice et al., 2004). In other words, results from previous studies identify reversed and bidirectional relationships between supportive relationships with parents and peers and depressive symptoms. Thus, the lack of supportive relationships and depression may fuel each other, forming a vicious cycle for affected adolescents. If patterns between supportive relationships with teachers and depressive symptoms in students exist as well, a lack of supportive relationships with teachers could magnify the risk for depression.

\section{Associations Between Supportive Relationships with Teachers and Depression in Adolescents}

Student sex is an important variable to consider when studying associations between supportive relationships with teachers and depressive symptoms in students. However, whether girls or boys benefit more from supportive relationships with teachers is an open question. For example, girls benefit more from parental support in middle adolescence (Kerr et al., 2006; Murberg \& Bru, 2004), while boys benefit more in late adolescence (Ystgaard et al., 1999). Research also shows that pubertal girls report more stressful events (Rudolph, 2002; Sawyer, Pfeiffer, \& Spence, 2009) and are more likely to develop depression than boys (Angold et al., 2002; Twenge \& Nolen-Hoeksema, 2002). Contrary to this, girls perceive higher levels of emotional support in their relationships than do boys (Johnson, 2004) and might be more vulnerable to depression if they lack or face problems with such relationships. Thus, one could just as well expect girls to benefit more than boys from support by teachers. This hypothesis is supported by multiple studies demonstrating that girls report more supportive relationships with teachers than do boys (Furrer \& Skinner, 2003; Niehaus, Rudasill, \& Rakes, 2012; Rueger et al., 2010; Shochet et al., 2011; Wentzel, Battle, Russell, \& Looney, 2010). Finally, in stressful situations, girls seek more emotional support from peers, while boys are more likely to seek instrumental support (Frey \& Röthlisberger, 1996). Thus, it is possible that the form of the associations between supportive relationships and depression in adolescents (main effect vs. interaction effect) differs depending on the type of support and the sex of the adolescent. Despite the open questions regarding sex as a possible moderator in the associations between supportive relationships with teachers and depressive symptoms in students, only four studies of teacher support and depression included sex in their analyses to date (Murberg \& Bru, 2004; Reddy, Rhodes, \& Mulhall, 2003; Rueger et al., 2010; Shochet et al., 2011).

In previous studies regarding the associations between supportive relationships with teachers and depression in adolescents, the principle-effect model was supported by two studies (including a cross-sectional study) for academic and emotional support (Murberg \& Bru, 2004) and emotional support (Reddy et al., 2003), respectively, in high school students of both sexes. In a study of middle school students measuring a mix of different types of support by teachers, however, this model was supported only for boys (Rueger et al., 2010). In another study with students in Grades 7 and 8, teacher emotional support predicted concurrent depression in both sexes, but not depression 1 year later (Shochet et al., 2011). In the only study test- ing the principle-effect model in students from Grades 5 to 12 (Barber \& Olsen, 2004), the model was supported for both boys and girls during transitions from elementary to middle school (Grades 5 to 6) and from middle to high school (Grades 8 to 9) when measuring perceptions of academic support. Further, the reversed principle-effect model is supported for middle school students of both sexes measuring appraisal, emotional, informational, and instrumental support (Reddy et al., 2003).

The purpose of the current study is to provide answers to remaining questions regarding teacher support and adolescent depression. First, is the relationship between teacher emotional support and depression in high school students bidirectional or unidirectional? If the latter is true, does teacher emotional support predict depression in high school students (principle-effect or stress-buffer model) or vice versa (reversed model)? Second, is teacher emotional support directly related to depression (principle-effect model), or is this association moderated by perceived stress, such that teacher emotional support is linked to depression only when perceived stress is high (stress-buffer model)? Third, does the same model provide the best explanation of the associations between supportive relationships with teachers and depression in high school students for boys and girls? Our hypotheses follow.

Hypothesis 1-Direction of the Associations: While empirical literature on supportive relationships with peers and depressive symptoms, especially in female middle school students, provides some evidence for bidirectional associations between both constructs (Prinstein et al., 2005; Stice et al., 2004), the only study examining bidirectional associations between teacher emotional support and adolescent depression found evidence for teacher support influencing depressive symptoms but not for reversed associations (Reddy et al., 2003). Thus, consistent with Reddy et al., 2003, we expect unidirectional associations such that higher teacher emotional support will predict lower adolescent depressive symptoms, but adolescent depression will not predict lower teacher support in high school students of both sexes.

Hypothesis 2-Social Support as Moderator and Sex Effects: Previous studies testing for both the principle-effect model (direct associations between teacher emotional support and depressive symptoms in high school students) and the stress-buffer model (associations between stressful life events and depressive symptoms in high school students moderated by teachers' emotional support; Murberg \& Bru, 2004, 2009) found support for both models. However, they did not compare the models, so it remains unclear whether one of these models describes the relationship between teacher emotional support and adolescent depression better than the other. In addition, while some studies' findings support the principle-effect model for both sexes (Murberg \& Bru, 2009; Reddy et al., 2003), Rueger et al. (2010) found support for this model in boys only, and Shochet et al. (2011) found support for this model for both sexes in the cross-sectional part of their study, but no support for this model longitudinally. The only study testing the stress-buffer model for boys and girls separately (Murberg \& Bru, 2004) found evidence for this model only in girls and not in boys (Murberg \& Bru, 2004). This is consistent with Frey and Röthlisberger's (1996) finding that girls, 
but not boys, try to increase the emotional support they receive from their family in stressful situations. Thus, it is possible that different models describe the associations between teacher support and depressive symptoms for boys and girls. Based on this and Hypothesis 1, we predict that the stress-buffer model will fit the data best for girls, while the principle-effect model will describe the nature of the associations best for boys.

\section{Method}

\section{Participants}

Participants were drawn from the beyondblue prevention study, a large scale depression prevention study conducted in Australia with students from 50 secondary schools. The prevention program comprised four elements, including (a) a classroom intervention aimed at improving problem solving and social skills, resilient thinking style, and coping strategies; (b) an element to build supportive environments (including decision making, conflict resolution, classroom discipline, staff relations, and antibullying); (c) an element to enhance partnerships between families, school staff, education support/welfare personnel, and community-based health professionals to facilitate students' access to professional services at school and in the wider community; and (d) community forums to provide students, their families, and school personnel with information to assist them with identifying problems, to seek help for themselves, and to help peers. Analyses revealed no significant differences in depressive symptoms and risk and protective factors experienced by students between intervention and control groups over a 3-year period (Sawyer et al., 2010). However, no separate analyses considering stressful situations in students were calculated.

Students in the study were followed from Grades 8 to 12 and completed a baseline assessment in the second term of Grade 8 (May and June 2003). At the baseline assessment, participants $(N=5,633)$ were an average age of $13.1(S D=$ $0.5)$ years old, and $47 \%$ were male. Demographic data indicated that $92 \%$ of the students were born in Australia, and $4.7 \%$ identified themselves as Aboriginal or Torres Straight Islander. Eighty-one percent of participants had at least one parent in full-time employment, while $70 \%$ of participants' parents lived together, consistent with national Australian population estimates (Australian Bureau of Statistics, 2003).

The academic year in Australia extends from February to early December, with Grade 8 typically being the first year of high school. Follow-up assessments took place in all schools in the last term of the school year (October through December) when the students were in Grades 9 to 12 . Of the baseline responders, $90.17 \%$ completed follow-up assessments in 2004, $79.87 \%$ did so in $2005,59.10 \%$ did so in 2006 , and $53.36 \%$ did so in 2007. This retention rate is comparable with other Australian longitudinal studies with adolescents and reflects the high mobility of the Australian society (e.g., Caldwell, Rudolph, Troop-Gordon, \& Kim, 2004; Heaven \& Ciarrochi, 2008). Informed consent was obtained from all participants and their parents prior to the baseline assessment.
Based on data of the departments of education of the participating states, 1,152 students left the school they attended at baseline sometime during the study. Thus, 4,481 students remained in the participating schools and formed the sample used in this study. The students left these schools for a variety of reasons (e.g., family relocation, changing to a vocational school, ${ }^{1}$ school dropout) and were excluded from the data analysis. No differences were found between students that left the school they attended at baseline and the remaining students with regard to sex, $\chi^{2}(1)=2.06, p=.358$, age, $t(5,473)=$ $0.94, p=.350$, and whether they were born in Australia or not, $\chi^{2}(2)=1.01, p=.604$. However, students who left their baseline school were significantly more often of Aboriginal and/ or Torres Strait Islander background, $\chi^{2}(1)=8.91, p=.012$, reported less supportive relationships with teachers at baseline, $t(1650.64)=4.03, p<.001$, reported more negative life events, $t(1550.15)=7.28, p<.001$, and reported a higher frequency of depressive symptoms, $t(1549.85)=-7.20, p<.001$.

\section{Measures}

Depressive symptoms. The Center for Epidemiological Studies Depression Scale (CES-D) was used to assess depressive symptoms at each time point. The CES-D consists of 20 items describing a wide range of depressive symptomatology (Radloff, 1991). To complete the measure, respondents rate their experience of each symptom in the past week on a 4-point scale from Rarely or none of the time (less than 1 day) to Most or all of the time (5-7 days). Summed scores can range from 0 to 60 , with higher scores indicating more depressive symptoms in the past week. Scores from the CES-D have strong reliability and construct validity in adolescents (Garrison, Schluchter, Schoenbach, \& Kaplan, 1989; Radloff, 1991). Cronbach's alpha in the beyondblue sample was between .92 and .94 in girls and between .88 and .91 in boys (see Table 1 ).

Life events. An adaptation of the List of Threatening Experiences Questionnaire (LTEQ) was used to measure 13 possible events with considerable long-term contextual threat (e.g., illness or death; pregnancy; problems with friends, law, or school; Brugha, Bebbington, Tennant, \& Hurry, 1985). Equivalent items were modified in their focus to be more appropriate for an adolescent group (e.g., split-up with boyfriend/ girlfriend rather than marital separation or divorce). Students answer yes or no regarding whether or not the event has happened in their lives within the past 6 months. Endorsed items are summed; total scores can range from 0 to 13 , with higher scores representing more life events. The original LTEQ demonstrated interrater agreements of kappa $=0.66$ to 0.84 between psychiatric patients and their relatives, sensitivity of 0.89 to 1.00 , and specificity of 0.74 to 0.88 based on the criterion of independently rated adversity derived from a semistructured life events interview (Brugha \& Cragg, 1990). Further, a previous publication demonstrated that the adapted version of the LTEQ predicts concurrent depressive symptoms and depressive symptoms 1 year later in high school students of both sexes (Sawyer et al., 2009). Mean number and standard deviation of endorsed stressful events separated by sex and grade level are reported in Table 1.

1. Students in Australia that are interested in a vocational career leave the general high school after Grade 10 and transition to specialized vocational high schools. 
Table 1. Descriptive Statistics (Age, Life-Events, Supportive Relationships With Teachers, and Depressive Symptoms) by Grade and Sex as Well as $t$ Tests Comparing Girls and Boys

\begin{tabular}{|c|c|c|c|c|c|c|c|c|}
\hline \multirow[b]{2}{*}{ Variable } & \multicolumn{3}{|c|}{ Girls } & \multicolumn{3}{|c|}{ Boys } & \multicolumn{2}{|c|}{$t$ tests } \\
\hline & $M$ & $S D$ & alpha & $M$ & $S D$ & alpha & $d f$ & $t$ value \\
\hline Age $\mathrm{t} 1$ & 13.15 & 3.16 & & 13.21 & 2.73 & & 4,339.00 & -0.57 \\
\hline Stress t2 & 1.70 & 1.62 & & 1.52 & 1.71 & & $3,964.00$ & $3.35^{\text {** }}$ \\
\hline Stress $\mathrm{t} 3$ & 1.68 & 1.63 & & 1.56 & 1.81 & & $3,338.62$ & $2.21^{*}$ \\
\hline Stress t4 & 1.49 & 1.49 & & 1.35 & 1.64 & & $2,565.00$ & $-2.31^{*}$ \\
\hline Support t2 & 24.17 & 5.56 & .89 & 23.42 & 5.80 & .90 & $3,910.94$ & $4.18^{* * *}$ \\
\hline Support $\mathrm{t} 3$ & 24.27 & 5.21 & .89 & 23.87 & 5.78 & .90 & $3,372.57$ & $2.18^{*}$ \\
\hline Support t4 & 25.85 & 5.21 & .90 & 25.23 & 5.28 & .90 & $2,585.00$ & $3.012^{* *}$ \\
\hline Support t5 & 26.62 & 4.82 & .89 & 25.88 & 5.25 & .90 & $1,985.20$ & $3.45^{* *}$ \\
\hline Depression $\mathrm{t} 1$ & 14.94 & 11.64 & .92 & 12.59 & 9.62 & .88 & $4,273.67$ & $7.26^{* * *}$ \\
\hline
\end{tabular}

For boys, $n=960$; for girls, $n=1,356$. Cronbach's alpha cannot be calculated for age or LTEQ. Support = supportive relationships with teachers score; Stress = List of Threatening Experiences Questionnaire; Depression = Center for Epidemiological Studies Depression Scale; $\mathrm{t} 1=$ Grade 8 ; $\mathrm{t} 2=$ Grade 9; $\mathrm{t} 3=$ Grade 10; $\mathrm{t} 4=$ Grade 11; $\mathrm{t} 5=$ Grade 12; LTEQ $=$ List of Threatening Experiences Questionnaire.

$+p<.10 ;{ }^{*} p<.05 ;{ }^{* *} p<.01 ;{ }^{* * *} p<.001$

Supportive relationships with teachers. An instrument to measure supportive relationships with teachers (emotional support) was developed for this study. Items were selected from existing scales (Arthur, Hawkins, Pollard, Catalano, \& Baglioni, 2002; Bond et al., 2004; Epstein \& McPartland, 1976; Goodenow, 1993; Roeser, Midgley, \& Urdan, 1996). Students used a 4-point scale (1-4) to rate the degree to which they agreed with each of the statements (sample item: "I feel I can go to my teacher with the things that are on my mind"), producing scores ranging from 9 to 36 . Cronbach's alpha in the total beyondblue sample was between .89 and .90 in girls and between .89 and .90 in boys (see Table 1$){ }^{2}$

\section{Design and Procedure}

Letters describing the study were sent to parents of all 8,873 students in Grade 8 of the participating schools. (For a detailed description of the eligibility criteria, the selection protocol, and the demographics of the participating schools, see Sawyer et al., 2009, 2010.). Parental consent was received for 5,633 (63\%) who were invited to participate. Students were assessed in classrooms or assembly halls during school time, and it took approximately $30 \mathrm{~min}$ to complete the measures. Students absent during the scheduled assessments were followed to minimize missing data. Students, parents, and teachers were not paid for their participation. The researchers administered the questionnaires, and teachers helped with maintaining control during instrument administration. Ethics approvals were obtained from the appropriate bodies in each state.

\section{Data Analysis}

Students who dropped out of the study were significantly more often of Aboriginal and/or Torres Strait Islander background, reported less supportive relationships with teachers at baseline, reported more negative life events, and reported a higher frequency of depressive symptoms compared with the retained students (see Participants section). Thus, the data of the dropped out students were deleted before computing multilevel models (Enders, 2001). Because students were nested in schools, HLM Version 6.03 (Raudenbush, Bryk, Cheong, Congdon, \& du Toit, 2004) was employed to examine effects of between-school differences. An unconditional means model revealed that variation in supportive teacher relationships between schools as measured by the intraclass correlation coefficient (ICC) is .0575 . Thus, only $5.75 \%$ of the total variability in supportive teacher relationships can be attributed to the schools. Similarly, the ICC of the unconditional means model with depressive symptoms is .0136 , or only $1.36 \%$ or the variability in depressive symptoms is between schools. As the variance in both variables explained by schools is less than $10 \%$, multilevel analyses accounting for nesting at the school level was deemed unnecessary (Lee, 2000).

Full information maximum likelihood (FIML) estimation was used to calculate path analyses (Arbuckle, 1999) with AMOS 18.0 because it is robust to missing data (Enders, 2001). Models' goodness of fit was tested with chi square, the rootmean-square error of approximation (RMSEA), and the comparative fit index (CFI). Furthermore, to determine the best fitting model, nested models were compared using chi-square difference tests. In the chi-square difference test, the chisquare values as well as the degrees of freedom of the models are subtracted from each other. When $\Delta \chi^{2}$ is significant for $\Delta d f$, the models are seen as significantly different from each other, and the model with fewer degrees of freedom fits the data better than the model with more degrees of freedom. When the

2. To determine the factor structure of this instrument, an exploratory factor analysis (EFA) and a confirmatory factor analysis (CFA) were employed. These results are presented in Supplement A. 
$\Delta \chi^{2}$ is not significant, both models fit equally well statistically, and the more parsimonious model (the model with more degrees of freedom) can be retained.

The different versions of the principle-effect model and the stress-buffer model were first calculated separately by sex. These models include the principle-effect model (unidirectional associations from teacher support at wave $X$ to depressive symptoms at wave $X+1$; Supplement B1), the reversed principle-effect model (unidirectional associations from depressive symptoms at wave $X$ to teacher support at wave $X+1$; Supplement B2), the bidirectional principle-effect model (teacher support at wave $X$ is associated with depressive symptoms at wave $X+1$ and depressive symptoms at wave $X$ are associated with teacher support at wave $X+1$; Supplement B3), the stress-buffer model (unidirectional associations from teacher support and teacher support by stressful events interactions at wave $X$ to depressive symptoms at wave $X+1$; Supplement B4), the reversed stress-buffer model (unidirectional associations from depressive symptoms and depressive symptoms by stressful events interactions at wave $X$ to teacher support at wave $X+$ 1; Supplement B5), and the bidirectional stress-buffer model (teacher support and teacher support by stressful events interactions at wave $X$ are associated with depressive symptoms at wave $X+1$ and depressive symptoms and depressive symptoms by stressful events interactions at wave $X$ are associated with teacher support at wave $X+1$; Supplement B6). Next, the models were compared with each other separately by sex using the chi-square difference test to determine which model fits the data best for boys and which model fits the data best for girls.

The interaction terms included in the models were analyzed by calculating $z$-scores for each of the variables contributing to the interaction, followed by multiplying the $z$ scores. In all models, latent random intercepts were modeled as predictors of each variable (depressive symptoms, stressful events, teacher support, Depressive Symptoms $\times$ Teacher Support, Stressful Events $\times$ Teacher Support) at every time point. The latent random intercepts assign each student a baseline for each variable across time. This allows for the measurement of the unexplained variance in relation to the individual rather than the sample as a whole. In other words, deviations from the latent intercept capture students' nonobserved differences while discriminating variability due to relationships of the observed variables. Thus, the use of a latent random intercept allows us to control for nonobserved confounding variables (Fergusson, Borden, \& Horwood, 2009; Hamerle \& Ronning, 1995), decreasing threats to validity. In addition, since being Aboriginal and/or Torres Strait Islander was associated with increased likelihood of dropping out of the study, Aboriginal and/or Torres Strait Islander status (yes/no) was added as an auxiliary variable in all analyses. Finally, all variables and the error terms of variables measured at one time point, respectively, were allowed to covary in all models.

\section{Results}

\section{Preliminary Analyses}

Descriptive statistics and correlations are shown in Table 1 and Supplement D. As expected, girls reported more stressful events, teacher emotional support, and depressive symptoms compared to boys. Also as expected, while most constructs correlated moderately with each other, age at Grade 8 did not correlate significantly with most other constructs.

\section{Hypothesis Testing}

To identify the model that fits the data best, six different models were tested separately by sex and compared with each other (Supplement E). First, the principle-effect model was compared with the stress-buffer model; boys: $\Delta \chi^{2}(4, N$ $=2,063)=24.92, p<.001$; girls: $\Delta \chi^{2}(4, N=2,278)=15.00, p<$ .001 , the reversed principle-effect model was compared with the reversed stress-buffer model; boys: $\Delta \chi^{2}(4, N=2,063)=$ 4.07, $p=.397$; girls: $\Delta \chi^{2}(4, N=2,278)=7.45, p=.114$, and the bidirectional principle-effect model was compared with the bidirectional stress-buffer model; boys: $\Delta \chi^{2}(8, N=2,063)=$ $30.63, p<.001$; girls: $\Delta \chi^{2}(8, N=2,278)=22.02, p<.001$. The $\chi^{2}$ difference tests supported the stress-buffer model, the reversed principle-effect model, and the bidirectional stressbuffer models for both sexes. Next, the stress-buffer models; boys: $\Delta \chi^{2}(8, N=2,063)=11.31, p=.185$; girls: $\Delta \chi^{2}(8, N$ $=2,278)=11.02, p=.201$, and the reversed principle-effect models; boys: $\Delta \chi^{2}(12, N=2,063)=33.56, p<.001$; girls: $\Delta \chi^{2}$ $(12, N=2,278)=28.09, p=.005$, were compared with the bidirectional stress-buffer model. The chi-square difference tests supported the stress-buffer models for both sexes, clearly demonstrating the superiority of the stress-buffer model.

With the stress-buffer model fitting best for both sexes, it was important to test for potential differences in this model between the sexes. Thus, a multiple group analysis comparing the fit of the stress-buffer model without any between-group constraints to the same model with increasing numbers of constraints was conducted. To test for statistical invariance, $\Delta \chi^{2}$-tests were used. However, as chi-square is known to increase with sample size (Jöreskog \& Sorbom, 1993), $\triangle$ CFI and $\triangle$ RMSEA were used to estimate practical invariance. Following Chen (2007) and Sass (2011), $\Delta$ CFI of < 0.01 and $\triangle$ RMSEA of $<0.015$ demonstrate practical invariance. Multiple group analyses comparing girls $(n=2,278)$ and boys $(n=2,063)$ indicated statistical and partially practical variance of the stress-buffer model across both sexes, $X_{\text {unconstrained }}^{2}(464)=1,506.40, p<.001$, CFI $(0.980)$, RMSEA $(0.023) ; \chi^{2}$ fully constrained $(609)=3,749.12, p<.001$, CFI $(0.941)$ RMSEA $(0.034) ; \Delta \chi^{2}(145)=2242.72, p<.001, \Delta$ CFI $(0.039)$, $\triangle$ RMSEA (0.011).

The individual paths between waves of the stress-buffer model for girls and boys are presented in Figure 1 and Figure 2 , respectively, and the correlations between the constructs within the waves are presented in Supplement F. A close inspection of the cross-wave paths relevant to the study's hypotheses revealed that none of the four paths from emotionally supportive relationships with teachers to depressive symptoms in high school students were significant for boys or girls. However, two of the four predicted paths from Teacher Support $\times$ Stressful Events to depression scores were significant for boys; for girls, this association was significant from Grade 8 to Grade 9. Nevertheless, it needs to be mentioned that the effect sizes of the paths from Teacher Support $\times$ Stressful Events to depression scores were significant but relatively modest. 


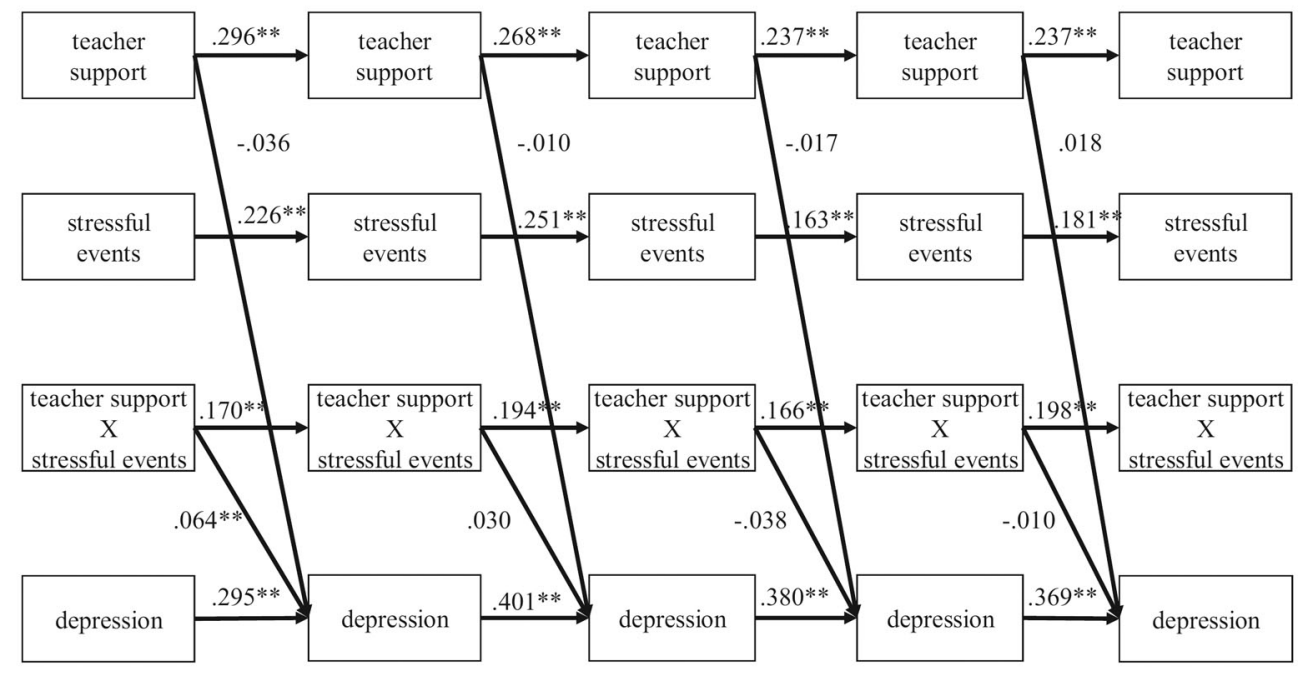

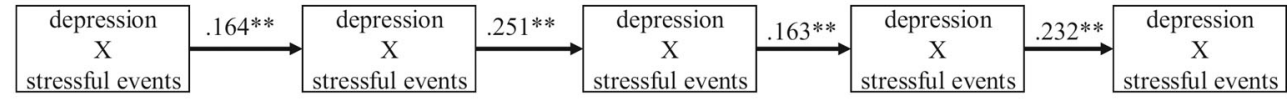

T1

T2

T3

T4

T5

Figure 1. Stress-buffer model for girls. All constructs and error terms of the constructs, respectively, measured at one time point are correlated. These correlations, the latent intercepts, and the auxiliary variable are not pictured for reasons of clarity. However, the correlations can be found in Supplement F. T = time ; ${ }^{*} p<.01 ; * * p<.001$

Model-implied graphs were constructed to examine the nature of the association between teacher support by stressful events interaction and depressive symptoms (Figures 3 \& 4). The graphs demonstrate that student perceptions of teacher emotional support was inversely associated with depressive symptoms 1 year later, even when the students faced average and high numbers of stressful events. This general trend was true for boys and girls. However, when the students experienced a low number of stressful life events, sex differences emerged. In girls experiencing a low number of stressful life events, an average level of teacher emotional support was associated with elevated depressive symptoms compared to low and high levels of teacher emotional support. In boys experiencing a low number of stressful life events, an almost linear negative association between teacher emotional support and depressive symptoms 1 year later emerged. ${ }^{3}$

\section{Discussion}

Extending the previous empirical literature on associations between teacher support and depressive symptoms in students (Barber \& Olsen, 2004; Murberg \& Bru, 2004, 2009; Reddy et al., 2003; Rueger et al., 2010; Shochet et al., 2011), the current 5-year longitudinal study with high school students is an investigation of the nature and direction of associations between teacher emotional support and adolescent depression for boys and girls. Based on findings from a lon- gitudinal study of teacher emotional support and depressive symptoms in middle school students (Reddy et al., 2003), we proposed unidirectional associations for both boys and girls such that greater teacher emotional support would be associated with lower levels of depressive symptoms in high school students but that adolescent depression would not predict teacher support (Hypothesis 1). In addition, we proposed that more teacher emotional support would mitigate the effects of stressful life events on depressive symptoms (unidirectional stress-buffer model) best for high school girls, while the unidirectional principle-effect model would fit the data best for boys (Hypothesis 2).

Consistent with Hypothesis 1, the model where greater teacher emotional support predicted lower levels of adolescent depression across time fit the data best for both girls and boys. However, the teacher support by stressful events interaction significantly predicted depressive symptoms from Grade 8 to Grade 9 for students of both sexes and from Grade 9 to Grade 10 for boys. More specifically, for boys and girls, increasing teacher support at one time point was associated with decreased depressive symptoms 1 year later. This association held up only in students with average and high numbers of stressful life events. For students reporting a low number of stressful life events, somewhat contrary findings emerged. For girls reporting low numbers of stressful events, average teacher emotional support was actually linked to more depressive symptoms than high or low teachers' emotional support. For boys re-

3. Results of additional analyses with imputed data, with only mixed gender schools, multigroup analyses with prevention and control group schools, and tests of whether paths vary across time are presented in Supplement C. 


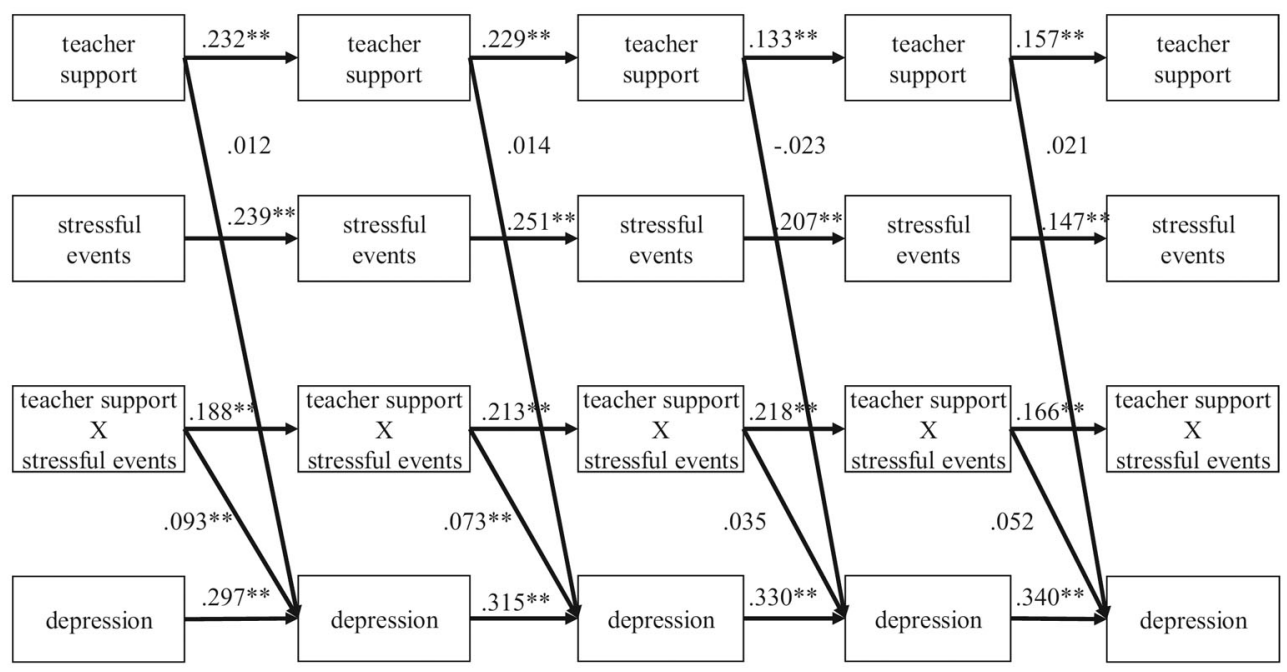

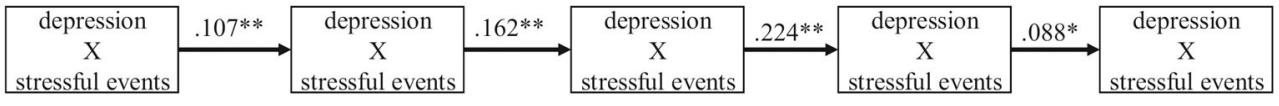

T1

T2

T3

T4

T5

Figure 2. Stress-buffer model for boys. All constructs and error terms of the constructs, respectively, measured at one time point are correlated. These correlations, the latent intercepts, and the auxiliary variable are not pictured for reasons of clarity. However, the correlations can be found in Supplement F. $\mathrm{T}=$ time $;{ }^{*} p<.01 ;{ }^{* *} p<.001$

porting low numbers of stressful events, more teacher support was associated with more depressive symptoms 1 year later. In other words, while the results suggest that the interaction of teacher support and life events impacted depressive symptoms in boys and girls, the interaction effect did not represent the expected stress-buffer effect of teacher support. In addition, it should be pointed out that the effect sizes of the interaction effects are relatively modest. A possible explanation for the unexpected finding regarding students with low numbers of stressful life events is that teacher emotional support has iatrogenic effects for those students. It would not be the first time that well intended actions show negative consequences. For example, negative effects of group interventions are well documented in adolescents with conduct problems (e.g.,

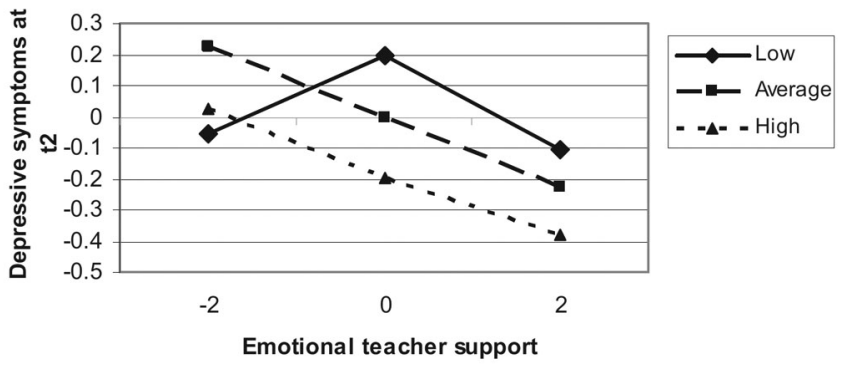

Figure 3. Model implied graph of the standardized interaction effect in girls. For the sake of comprehension and simplicity, the graphs were calculated with standard deviations of $-2,0$, and 2 on both standardized teacher emotional support and standardized stressful events. $\mathrm{t}=$ time.
Gifford-Smith, Dodge, Dishion, \& McCord, 2005; Mager, Milich, Harris, M. J., \& Howard, 2005). Cross-age peer mentoring programs (Karcher, Davidson, Rhodes, \& Herrera, 2010) and programs to prevent adolescent depression (Pössel, Horn, Groen, \& Hautzinger, 2004; Pössel, Martin, Garber, \& Hautzinger, 2012) also have the potential to produce iatrogenic effects. Especially important for the present findings is that students reporting fewer problems at the study beginning demonstrated an increase in problems, while students with more problems at the study beginning did not demonstrate such an increase (Karcher et al., 2010; Mager et al., 2005). In addition, research demonstrates that the level of friend-reported depressive symptoms among members of adolescents' peer cliques is associated longitudinally with changes in adolescents' own self-reported depressive symptoms (Prinstein, 2007). These patterns can be explained by the so-called deviancy training hypothesis, which states that students are role models for each other, learning to attend to or describe depressive symptoms. Regarding our finding in the present study, this could mean that teacher emotional support provides the space for such learning, as it allows students to express their problems in a public forum. This interpretation is consistent with a study that found short-term iatrogenic effects of an emotionally supportive prevention program of depression in adolescents (Pössel et al., 2012). Nevertheless, the finding that emotional teacher support might have iatrogenic effects on depressive symptoms in students with low numbers of stressful life events needs to be interpreted cautiously until explored further. 
Effect of teacher support by stressful event at $t 1$ on depressive symptoms at $\mathbf{t} 2$

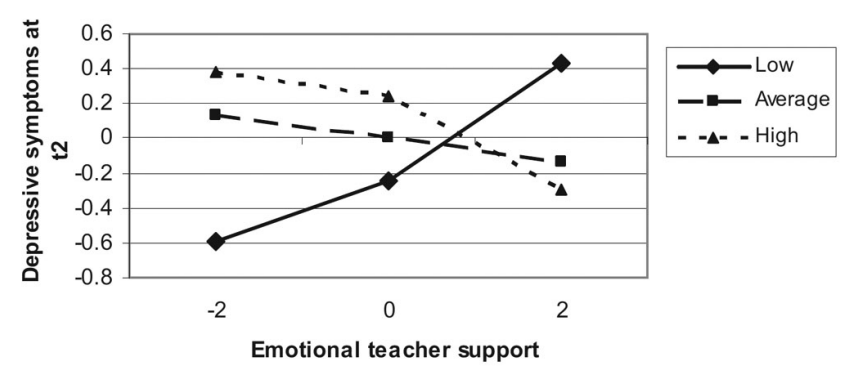

Effect of teacher support by stressful event at $t 2$ on depressive symptoms at $\mathrm{t} 3$

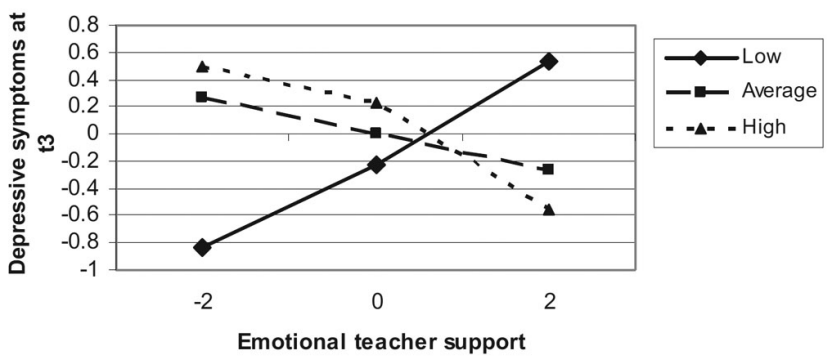

Figure 4. Model implied graphs of the standardized interaction effect in boys. For the sake of comprehension and simplicity, the graphs were calculated with standard deviations of $-2,0$, and 2 on both standardized teacher emotional support and standardized stressful events. $\mathrm{t}=$ time.

Our finding that the same model describes the associations best for both girls and boys is not consistent with our hypothesis. However, it should be pointed out that previous findings on sex differences in the relationships between students and adults (parents, teachers) are mixed (Kerr et al., 2006; Murberg \& Bru, 2004; Shochet et al., 2011; Ystgaard et al., 1999). This raises questions about potential causes of this inconsistent pattern. Inspecting the literature, it seems that girls benefit more in middle adolescence from adult support (Kerr et al., 2006; Murberg \& Bru, 2004), while boys benefit more from adult support in late adolescence (Ystgaard et al., 1999). This observation seems consistent with the fact that girls develop 1-2 years earlier than boys do (Patton \& Viner, 2007), suggesting that this earlier development is connected with earlier independence from adult support. This difference in development could also explain why the interaction of teacher emotional support and stressful events only predicts depressive symptoms in Grade 9 in girls while it predicts depressive symptoms up to Grade 10 in boys. However, empirical research does not support the expectation that girls become independent from adult support earlier than boys without reservation. For example, a study with 12- to 18-year-olds showed a positive association between age and supportive peer relationships but not age and supportive parental relationships (Kerr et al., 2006). Thus, further research studying possible sex effects on the associations between teacher support by stressful events and depressive symptoms is needed.

Of further interest, girls reported more stressful events and depressive symptoms than did boys across all grades of high school. This is not entirely unexpected, as several studies have demonstrated similar findings (e.g., Angold et al., 2002; Rudolph, 2002; Sawyer et al., 2009; Twenge \& Nolen-Hoeksema, 2002). Further, the finding that girls in Grades 9 to 12 reported more emotionally supportive relationships with teachers than boys expands on other work (e.g., Furrer \& Skinner, 2003; Rueger et al., 2010; Shochet et al., 2011; Wentzel, Battle, Russell, \& Looney, 2010) in which girls have reported more supportive relationships with teachers than have boys. Thus, results reported herein, together with results from other work, suggest that, although girls report more teacher emotional support than boys throughout high school, this does not seem to completely protect them from developing depressive symptoms. There appear to be other factors that contribute to girls' increased likelihood of depression in adolescence, such as the fact that girls have lower global self-worth and domain-specific self-perceptions during adolescence (Harter, 2006) and are more vulnerable to negative self-appraisals regarding body image (Ruble, Martin, \& Berenbaum, 2006).

Strengths of the present study include a large sample size and a five-wave longitudinal design that allowed us to follow students during their entire high school career. These strengths allowed us to draw conclusions about the directionality of relationships between teacher support and adolescent depressive symptoms across high school. In addition, the use of a community sample allows our results to be less vulnerable to a selection bias. In other words, because individuals with depressive disorders are systematically different from the general population, findings in a community sample are more generalizable because they can be applied to a larger number of individuals (P. Cohen \& Cohen, 1984).

Several limitations of this study should be noted. First, and as already mentioned, the sole usage of student reports might cause an overestimation of the associations between teacher support, stressful events, and depressive symptoms. Second, more evidence on the validity of the instrument to measure teacher support is needed. However, some construct validity evidence by two different factor analyses and practical metric invariance across sex (girls vs. boys), condition (prevention vs. control condition), and time (grade 8 vs. grade 12) exists. However, this evidence is especially limited because all reported analyses used the beyondblue sample, and validity evidence using other samples is clearly needed. Third, as depressive symptoms were assessed using a checklist rather than a diagnostic interview, it is unclear whether findings can be generalized to adolescents with clinical levels of depression. Nevertheless, most research suggests that adolescent depression can be seen best as dimensional (e.g., Hankin, Fraley, Lahey, \& Waldman, 2005), making it likely that our results could be replicated in a sample with depressive disorders.

Another important limitation is the high, nonrandom drop-out rate of $46.63 \%$. More students of Aboriginal and/ or Torres Strait Islander background and more students who reported less supportive relationships with teachers at baseline, more negative life events, and/or a higher frequency of depressive symptoms left their baseline school. However, it needs to be considered that students in Australia interested in a vocational career leave the general high school after Grade 10 and transition to specialized vocational high schools. This explains the $20 \%$ drop in participation rate from Grade 10 grade 11. In addition, in Australia, students of Aboriginal background transfer more often into vocational schools or drop out of schools entirely (Gray, Huber, \& Schwab, 2000). 
Similarly, adolescents who report less teacher support (Davis \& Dupper, 2004), experience more negative life events (Dyregrov, 2004), or suffer from depressive symptoms (Fortin, Marcotte, Potvin, Royer, \& Joly, 2006; Lewinsohn \& Clarke, 1999) change schools and drop out of school more often than other students. Nevertheless, such patterns limit the generalizability of the findings to these groups. Thus, future research concerning teacher support and depressive symptoms with such students is essential.

The results are not only important from an academic point of view but also for clinical purposes. Combined with previous studies on the association between teacher support and depressive symptoms in students (Barber \& Olsen, 2004; Murberg \& Bru, 2004, 2009; Reddy et al., 2003; Rueger et al., 2010; Shochet et al., 2011), our findings that the negative impact of average and high numbers of stressful events on students is reduced by teacher emotional support highlight the importance of teachers' emotional support for students in stressful situations. However, if replicated, the finding that teacher emotional support can have iatrogenic effects on students with low numbers of stressful life events is important as well. It seems worth considering how teacher emotional support can be used in depression prevention programs for high school students without harming some students.

First, based on the present findings, a prevention program using emotional support by teachers should be implemented in the first year of high school to benefit both girls and boys. Second, it is important to include a way to identify students in stressful situations that will allow teachers to focus especially on these students. Third, it is necessary to identify ways to provide emotional teacher support to those identified students without harming students with low numbers of stressful life events. Thus, research studying the mechanisms by which emotional teacher support might have iatrogenic effects on students experiencing low numbers of stressful life events is needed. Fourth, the sex of the teachers and the match between student and teacher sex might be relevant for the effect of teacher support on depressive symptoms in students. However, the instrument used to measure the emotional support from teachers did not include an item querying teacher sex. It is up to future research to study the relevance of teacher's sex and match between student-teacher sex for the effects of teacher support on depressive symptoms in students.

In summary, while the effect sizes of the associations between the interactions of teacher support and life events with depressive symptoms were relatively modest, data from this study support the importance of the interplay between teacher emotional support and life events for male and female high school students' depressive symptomatology, but only in the early grades of high school. Further, while students with average and high numbers of stressful life events seem to benefit from emotional teacher support, supportive relationships with teachers seem to bear a risk for negative effects on depressive symptoms in students experiencing a low number of stressful life events. Thus, future studies designed to identify the underlying mechanisms by which emotional teacher support impacts students depressive symptoms in a positive and a negative way using multiple student- and teacher-report instruments is needed. In these studies, possible sex differences in the associations between teacher support and students' depressive symptoms should be studied carefully. Further, the associations between other types of support (i.e., academic, appraisal, instrumental, and informational) and depression in students should be explored. Finally, recent advances in analyzing longitudinal models like latent change score models (e.g., Ferrer \& McArdle, 2010) should be used in future studies.

\section{References}

Abela, J. R. Z., \& Sullivan, C. (2003). A test of Beck's cognitive diathesis-stress theory of depression in early adolescents. The Journal of Early Adolescence, 23, 384-404. doi: 10.11770272431603258345

Abela, J. R. Z., Vanderbilt, E., \& Rochon, A. (2004). A test of the integration of the response styles and social support theories of depression in third and seventh grade children. Journal of Social and Clinical Psychology, 23, 653-674. doi: 10.1521/jscp.23.5.653.50752

American Psychiatric Association. (2000). Diagnostic and statistical manual of mental disorders (4th ed., text rev.). Washington, DC: APA.

Angold, A., Erkanli, A., Silberg, J., Eaves, L., \& Costello, E. J. (2002). Depression scale scores in 8-17-year-olds: Effects of age and gender. Journal of Child Psychology and Psychiatry, 43, 1052-1063. doi: 10.1111/1469-7610.00232

Arbuckle, J. L. (1999). AMOS user's guide. Chicago, IL: SmallWaters.

Arthur, M. W., Hawkins, J. D., Pollard, J. A., Catalano, R. F., \& Baglioni, A. J., Jr. (2002). Measuring risk and protective factors for substance use, delinquency, and other adolescent problem behaviors: The Communities That Care Youth Survey. Evaluation Review, 26, 575-601.

Australian Bureau of Statistics. (2003). Census of population and housing - Socio-economic indexes for areas, Australia. Canberra, Australia: Australian Bureau of Statistics.

Barber, B. K., \& Olsen, J. A. (2004). Assessing the transitions to middle and high school. Journal of Adolescent Research, 19, 3-30. doi: 10.1177/0743558403258113

Beck, A. T. (1976). Cognitive therapy and the emotional disorders. New York, NY: International University Press.

Bond, L., Patton, G., Glover, S., Carlin, J. B., Butler, H., Thomas, L., \& Bowes, G. (2004). The Gatehouse Project: Can a multi-level school intervention affect emotional well being and health risk behaviours? Journal of Epidemiology and Community Health, 58, 997-1003. doi: 10.1136/jech.2003.009449

Brown, G. W., \& Harris, T. O. (1978). Social origins of depression. London, England: Free Press.

Brugha, T., Bebbington, P., Tennant, C., \& Hurry, J. (1985). The List of Threatening Experiences: A subset of 12 life event categories with considerable long-term contextual threat. Psychological Medicine, 15, 189-194. doi: 10.1017/S003329170002105X

Brugha, T. S., \& Cragg, D. (1990). The List of Threatening Experiences: The reliability and validity of a brief life events questionnaire. Acta Psychiatrica Scandinavica, 82, 77-81. doi: 10.1111/j.16000447.1990.tb01360.x

Caldwell, M. S., Rudolph, K. D., Troop-Gordon, W., \& Kim, D.-Y. (2004). Reciprocal influences among relational self-views, social disengagement, and peer stress during early adolescence. Child Development, 75, 1140-1154. doi: 10.1111/j.1467-8624.2004.00730.x

Chen, F. F. (2007). Sensitivity of goodness of fit indexes to lack of measurement invariance. Structural Equation Modeling, 14, 464-504. doi: 10.1080/10705510701301834

Cohen, P., \& Cohen, J. (1984). The clinician's illusion. Archives of General Psychiatry, 41, 1178-1182. doi: 10.1001/ archpsyc.1984.01790230064010

Cohen, S., \& McKay, G. (1984). Social support, stress, and the buffering hypothesis: A theoretical analysis. In A. Baum, J. E. Singer, \& S. E. Taylor (Eds.), Handbook of psychology and health (Vol. 4). Hillsdale, NJ: Erlbaum. 
Cohen, S., \& Wills, T. A. (1985). Stress, social support, and the buffering hypothesis. Psychological Bulletin, 98, 310-357. doi: 10.1037/0033- 2909.98.2.310

Cutrona, C. E., \& Troutman, B. R. (1986). Social support, infant stress, and parenting self-efficacy: A mediational model of postpartum depression. Child Development, 57, 1507-1518.

Davis, K. S., \& Dupper, D. R. (2004). Student-teacher relationships: An overlooked factor in school dropout. Journal of Human Behavior in the Social Environment, 9, 179-193. doi: 10.1300/J137v09n01_12

Desjardins, T. L., \& Leadbeater, B. J. (2011). Relational victimization and depressive symptoms in adolescence: Moderating effects of mother, father, and peer emotional support. Journal of Youth and Adolescence, 40, 531-544. doi: 10.1007/s10964-010-9562-1

Dumont, M., \& Provost, M. A. (1999). Resilience in adolescents: Protective role of social support, coping strategies, self-esteem, and social activities on experience of stress and depression. Journal of Youth and Adolescence, 28, 343-363. doi: 10.1023/ A:1021637011732

Dunn, V., \& Goodyer, I. M. (2006). Longitudinal investigation into childhood- and adolescence-onset depression: Psychiatric outcome in early adulthood. The British Journal of Psychiatry, 188, 216222. doi: $10.1192 /$ bjp.188.3.216

Dyregrov, A. (2004). Educational consequences of loss and trauma. Educational and Child Psychology, 21, 77-84.

Enders, C. K. (2001). A primer on maximum likelihood algorithms available for use with missing data. Structural Equation Modeling, 8, 128- 141. doi: 10.1207/S15328007SEM0801_7

Epstein, J. L., \& McPartland, J. M. (1976). The concept and measurement of the quality of school life. American Educational Research Journal, 13, 15-30.

Fergusson, D. M., Boden, J. M., \& Horwood, L. J. (2009). Tests of causal links between alcohol abuse or dependence and major depression. Archives of General Psychiatry, 66, 260-266. doi: 10.1001/ archgenpsychiatry.2008.543

Ferrer, E., \& McArdle, J. J. (2010). Longitudinal modeling of developmental changes in psychological research. Current Directions in Psychological Science, 19, 149-154. doi: 10.1177/0963721410370300

Fortin, L., Marcotte, D., Potvin, P., Royer, É., \& Joly, J. (2006). Typology of students at risk of dropping out of school: Description by personal, family and school factors. European Journal of Psychology of Education, 21, 363-383. doi: 10.1007/BF03173508

Frey, C. U., \& Röthlisberger, C. (1996). Social support in healthy adolescents. Journal of Youth and Adolescence, 25, 17-31. doi: 10.1007/ BF01537378

Furrer, C., \& Skinner, E. (2003). Sense of relatedness as a factor in children's academic engagement and performance. Journal of Educational Psychology, 95, 148-162. doi: 10.1037/0022-0663.95.1.148

Garrison, C. Z., Schluchter, M. D., Schoenbach, V. J., \& Kaplan, B. K. (1989). Epidemiology of depressive symptoms in young adolescents. Journal of the American Academy of Child \& Adolescent Psychiatry, 28, 343-351. doi: 10.1097/00004583-198905000-00007

Gifford-Smith, M., Dodge, K. A., Dishion, T. J., \& McCord, J. (2005). Peer influence in children and adolescents: Crossing the bridge from developmental to intervention science. Journal of Abnormal Child Psychology, 33, 255-265. doi: 10.1007/s10802-005-3563-7

Goodenow, C. (1993). The psychological sense of school membership among adolescents: Scale development and educational correlates. Psychology in the Schools, 30, 79-90. doi: 10.1002/1520-6807(199301)30:1<79::AID-PITS2310300113 $>3.0 . \mathrm{CO} ; 2-\mathrm{X}$

Gray, M. C., Huber, B., \& Schwab, R. G. (2000). Trends in indigenous educational participation and attainment, 1986-96. Australian Journal of Education, 44, 101-117.

Hamerle, A., \& Ronning, G. (1995). Panel analysis for qualitative variables. In G. Arminger, C. C. Clogg, \& M. E. Sobel (Eds.), Handbook of statistical modeling for the social and behavioral sciences (pp. 401451). New York, NY: Plenum Press.

Hammen, C. (2005). Stress and depression. Annual Review of Clinical Psychology, 1, 293-319. doi: 10.1146/annurev. clinpsy.1.102803.143938

Hankin, B. L., Fraley, R. C., Lahey, B. B., \& Waldman, I. (2005). Is youth depressive disorder level best viewed as a continuum or discrete category? A taxometric analysis of childhood and adolescent depression in a population-based sample. Journal of Abnormal Psychology, 114, 96- 110. doi: 10.1037/0021-843X.114.1.96

Harris, T. O., Borsanyi, S., Messari, S., Stanford, K., Brown, G. W., Cleary, S. E., . . Herbert, J. (2000). Morning cortisol as a risk factor for subsequent major depressive disorder in adult women. The British Journal of Psychiatry, 177, 505-510. doi: 10.1192/ bjp.177.6.505

Harter, S. (2006). The self. In N. Eisenberg (Ed.), Social, emotional, and personality development (6th ed., Vol. 3, pp. 505-570). New York, NY: Wiley.

Heaven, P. C. L., \& Ciarrochi, J. (2008). Parental styles, conscientiousness, and academic performance in high school: A three-wave longitudinal study. Personality and Social Psychology Bulletin, 34, 451461. doi: 10.1177/0146167207311909

Johnson, H. D. (2004). Gender, grade, and relationship differences in emotional closeness within adolescent friendships. Adolescence, 39, 243-255.

Joiner, T. E., Jr., \& Metalsky, G. I. (2001). Excessive reassurance seeking: Delineating a risk factor involved in the development of depressive symptoms. Psychological Science, 12, 371-378. doi: 10.1111/1467-9280.00369

Jöreskog, K. G., \& Sorbom, D. (1993). LISREL 8: Structural equation modeling with the SIMPLIS command language. Chicago, IL: Scientific Software International.

Karcher, M. J., Davidson, A. J., Rhodes, J. E., \& Herrera, C. (2010). Pygmalion in the program: The role of teenage per mentors' attitudes in shaping their mentees' outcomes. Applied Developmental Science, 14, 212-227. doi: 10.1080/10888691.2010.516188

Kerr, D. C. R., Preuss, L. J., \& King, C. A. (2006). Suicidal adolescents' social support from family and peers: Gender-specific associations with psychopathology. Journal of Abnormal Child Psychology, 34, 99-110. doi: 10.1007/s10802-005-9005-8

Lee, V. E. (2000). Using hierarchical linear modeling to study social contexts: The case of school effects. Educational Psychologist, 35, 125-141. doi: 10.1207/S15326985EP3502_6

Lewinsohn, P. M., \& Clarke, G. M. (1999). Psychosocial treatments for adolescent depression. Clinical Psychology Review, 19, 329-342. doi: 10.1016/S0272-7358(98)00055-5

Lewinsohn, P. M., Hoberman, H. M., Teri, L., \& Hautzinger, M. (1985). An integrated theory of depression. In S. Reiss \& R. Bootzin (Eds.), Theoretical issues in behavior therapy (pp. 331-359). New York, NY: Academic Press.

Lewinsohn, P. M., Joiner, T. E., Jr., \& Rohde, P. (2001). Evaluation of cognitive diathesis-stress models in predicting major depressive disorder in adolescents. Journal of Abnormal Psychology, 110, 203215. doi: 10.1037/0021-843X.110.2.203

Mager, W., Milich, R., Harris, M. J., \& Howard, A. (2005). Intervention groups for adolescents with conduct problems: Is aggregation harmful or helpful? Journal of Abnormal Child Psychology, 33, 349362. doi: $10.1007 /$ s10802-005-3572-6

Malecki, C. K., \& Demaray, M. K. (2002). Measuring perceived social support: Development of the Child and Adolescent Social Support Scale (CASSS). Psychology in the Schools, 39, 1-18. doi: 10.1002/ pits.10004

Murberg, T. A., \& Bru, E. (2004). Social support, negative life events and emotional problems among Norwegian ado- 
lescents. School Psychology International, 25, 387-403. doi: $10.1177 / 0143034304048775$

Murberg, T. A., \& Bru, E. (2009). The relationship between negative life events, perceived support in the school environment and depressive symptoms among Norwegian senior high school students: A prospective study. Social Psychology of Education, 12, 361370. doi: 10.1007/s11218-008-9083-x

Niehaus, K., Rudasill, K. M., \& Rakes, C. (2012). A longitudinal study of school connectedness and academic outcomes across sixth grade. Journal of School Psychology, 50, 443-460. doi: 10.1016/j. jsp.2012.03.002

Patton, G. C., \& Viner, R. (2007). Pubertal transitions in health. Lancet, 369, 1130-1139. doi: 10.1016/S0140-6736(07)60366-3

Pössel, P., Adelson, J., \& Hautzinger, M. (2011). A randomized trail to evaluate the course of effects of a program to prevent adolescent depressive symptoms over 12-months. Behaviour Research and Therapy, 49, 838-851. doi: 10.1016/j.brat.2011.09.010

Pössel, P., Horn, A. B., Groen, G., \& Hautzinger, M. (2004). Schoolbased universal primary prevention of depressive symptoms in adolescents: Results of a 6-month follow-up. Journal of the American Academy of Child \& Adolescent Psychiatry, 43, 1003-1010. doi: 10.1097/01.chi .0000126975.56955.98

Pössel, P., Martin, N. C., Garber, J., \& Hautzinger, M. (2012). A randomized controlled trial comparing a cognitive-behavioral to a nonspecific program for the prevention of depression in adolescents. Manuscript submitted for publication.

Pössel, P., Seemann, S., \& Hautzinger, M. (2008). Impact of comorbidity in prevention of adolescent depressive symptoms. Journal of Counseling Psychology, 55, 106-117. doi: 10.1037/0022-0167.55.1.106

Prinstein, M. J. (2007). Moderators of peer contagion: A longitudinal examination of depression socialization between adolescents and their best friends. Journal of Clinical Child and Adolescent Psychology, 36, 159-170. doi: 10.1080/15374410701274934

Prinstein, M. J., Borelli, J. L., Cheah, C. S. L., Simon, V. A., \& Aikins, J. W. (2005). Adolescent girls' interpersonal vulnerability to depressive symptoms: A longitudinal examination of reassurance-seeking and peer relationships. Journal of Abnormal Psychology, 114, 676-688. doi: 10.1037/0021-843X.114.4.676

Radloff, L. S. (1991). The use of the Center for Epidemiologic Studies Depression Scale in adolescents and young adults. Journal of Youth and Adolescence, 20, 149-166. doi: 10.1007/BF01537606

Raudenbush, S., Bryk, A., Cheong, Y. F., \& Congdon, R., \& du Toit, M. (2004). HLM6: Hierarchical linear and non-linear modeling. Lincolnwood, IL: Scientific Software International.

Reddy, R., Rhodes, J. E., \& Mulhall, P. (2003). The influence of teacher support on student adjustment in the middle school years: A latent growth curve study. Development and Psychopathology, 15, 119138. doi: $10.1017 /$ S0954579403000075

Roeser, R. W., Midgley, C., \& Urdan, T. C. (1996). Perceptions of the school psychological environment and early adolescents' psychological and behavioral functioning in school: The mediating role of goals and belonging. Journal of Educational Psychology, 88, 408422. doi: $10.1037 / 0022-0663.88 .3 .408$

Ruble, D. N., Martin, C. L., \& Berenbaum, S. A. (2006). Gender development. In N. Eisenberg (Ed.), Social, emotional, and personality development (6th ed., Vol. 3, pp. 858-932). New York, NY: Wiley.
Rudolph, K. D. (2002). Gender differences in emotional responses to interpersonal stress during adolescence. Journal of Adolescent Health, 30, 3-13. doi: 10.1016/S1054-139X(01)00383-4

Rudolph, K. D., Flynn, M., \& Abaied, J. L. (2008). A developmental perspective on interpersonal theories of youth depression. In J. R. Z. Abela \& B. L. Hankin (Eds.), Handbook of depression in children and adolescents (pp. 79-102). New York, NY: Guilford Press.

Rueger, S. Y., Malecki, C. K., \& Demaray, M. K. (2008). Gender differences in the relationship between perceived social support and student adjustment during early adolescence. School Psychology Quarterly, 23, 496-514. doi: 10.1037/1045-3830.23.4.496

Rueger, S. Y., Malecki, C. K., \& Demaray, M. K. (2010). Relationship between multiple sources of perceived social support and psychological and academic adjustment in early adolescence: Comparisons across gender. Journal of Youth and Adolescence, 39, 47-61. doi: 10.1007/s10964-008-9368-6

Sass, D. A. (2011). Testing measurement invariance and comparing latent factor means within a confirmatory factor analysis framework. Journal of Psychoeducational Assessment, 29, 347-363.

Sawyer, M. G., Pfeiffer, S., \& Spence, S. H. (2009). Life events, coping and depressive symptoms among young adolescents. A one-year prospective study. Journal of Affective Disorders, 117, 48-54. doi: 10.1016/ j.jad.2008.12.013

Sawyer, M. G., Pfeiffer, S., Spence, S. H., Bond, L., Graetz, B., Kay, D., ... Sheffield, J. (2010). School-based prevention of depression: A randomised controlled study of the beyondblue schools research initiative. Journal of Child Psychology and Psychiatry, 51, 199-209. doi: 10.1111/j.1469-7610.2009.02136.x

Shochet, I. M., Smith, C. L., Furlong, M. J., \& Homel, R. (2011). A prospective study investigating the impact of school belonging factors on negative affect in adolescents. Journal of Clinical Child and Adolescent Psychology, 40, 586-595. doi: 10.1080/15374416.2011.581616

Stice, E., Ragan, J., \& Randall, P. (2004). Prospective relations between social support and depression: Differential direction of effects for parent and peer support? Journal of Abnormal Psychology, 113, 155159. doi: 10.1037/0021-843X.113.1.155

Twenge, J. M., \& Nolen-Hoeksema, S. (2002). Age, gender, race, socioeconomic status, and birth cohort differences on the Children's Depression Inventory: A meta-analysis. Journal of Abnormal Psychology, 111, 578-588. doi: 10.1037/0021-843X.111.4.578

Wentzel, K., Battle, A., Russell, S., \& Looney, L. (2010). Social supports from teachers and peers as predictors of academic and social motivation. Contemporary Educational Psychology, 35, 193-202. doi: 10.1016/j.cedpsych.2010.03.002

Yang, J., Yao, S., Zhu, X., Zhang, C., Ling, Y., Abela, J. R. Z., ... McWhinnie, C. (2010). The impact of stress on depressive symptoms is moderated by social support in Chinese adolescents with subthreshold depression: A multi-wave longitudinal study. Journal of Affective Disorders, 127, 113-121. doi: 10.1016/j.jad.2010.04.023

Young, J. F., Berenson, K., Cohen, P., \& Garcia, J. (2005). The role of parent and peer support in predicting adolescent depression: A longitudinal community study. Journal of Research on Adolescence, 15, 407- 423. doi: 10.1111/j.1532-7795.2005.00105.x

Ystgaard, M., Tambs, K., \& Dalgard, O. S. (1999). Life stress, social support and psychological distress in late adolescence: A longitudinal study. Social Psychiatry and Psychiatric Epidemiology, 34, 1219. doi: $10.1007 / \mathrm{s} 001270050106$ 


\section{Supplement A}

To determine the factor structure of this instrument, an exploratory factor analysis (EFA) and a confirmatory factor analysis (CFA) was employed. Thus, the beyondblue sample at baseline was randomly split into two subsamples. An exploratory factor analysis (EFA) with principal axis factoring was conducted with one half $(n=2,821)$. Bartlett's test of sphericity $(\chi 2=11476.40, d f=36, p<.001)$ and the Kaiser-MeyerOlkin measure of sampling adequacy (.929), suggested the data were suitable for EFA (Pett, Lackey, \& Sullivan, 2003). To determine the number of factors to extract, the Kaiser-Guttman criterion and the scree test were applied. Both criteria suggested a one factor solution. This factor had an eigenvalue of 4.88 and explained $54.26 \%$ of the variance. The factor loadings of the 9 items on this factor were between .49 and .78 . A CFA with the one-factor model was conducted with the other half of the sample. The one-factor model $\left(\chi^{2}[27, N=2,777]=501.30, p<.001\right)$, exhibited acceptable model fit: $\mathrm{CFI}=.957, \mathrm{RMSEA}=.080)$. The standardized regression weights between the factor and the 9 items ranged from .43 to .79 .

Further, using the total beyondblue sample $(N=5,633)$ the metric invariance across sex (girls vs. boys), condition (prevention vs. control condition), and time (grade 8 vs. grade 12) was tested. To do this, multiple group analyses comparing the fit of the one-factor model without any between-group constraints to the same model with measurement weights being constrained to be equal across groups were conducted. $\Delta \chi^{2}-$ tests, $\triangle \mathrm{CFI}$, and $\triangle \mathrm{RMSEA}$ were used to estimate invariance; $\triangle \mathrm{CFI}$ of $<0.01$ and $\triangle$ RMSEA of $<0.015$ (Chen, 2007; Sass, 2011). Multiple group analyses comparing girls $(n=2,937)$ and boys $(n=2,622)$ indicated metric invariance of the one-factor model 
across both sexes $\left(\Delta \chi^{2}(8)=9.34, p=.314, \Delta\right.$ CFI (0.000), $\Delta$ RMSEA (0.004)). Multiple group analyses comparing students in the control $(n=2,582)$ and prevention condition $(n$ $=3,016)$ supported metric invariance of the one-factor model across both conditions $\left(\Delta \chi^{2}(8)=17.29, p=.027, \Delta\right.$ CFI $(0.001), \Delta$ RMSEA (0.004)). Similarly, a comparison of students in grade 8 with themselves in grade $12(n=5,598)$ supported metric invariance of the one-factor model across time $\left(\Delta \chi^{2}(8)=75.48, p<.001, \Delta \mathrm{CFI}(0.002), \Delta \mathrm{RMSEA}\right.$ (0.003)). Thus, the one-factor model is interpreted as invariant across conditions and time.

\section{Reference}

Pett, M. A., Lackey, N. R., \& Sullivan, J. J. (2003). Making sense of factor analysis: The use of factor analysis for instrument development in health care research. Thousand Oaks, CA: Sage. 
Supplement B 


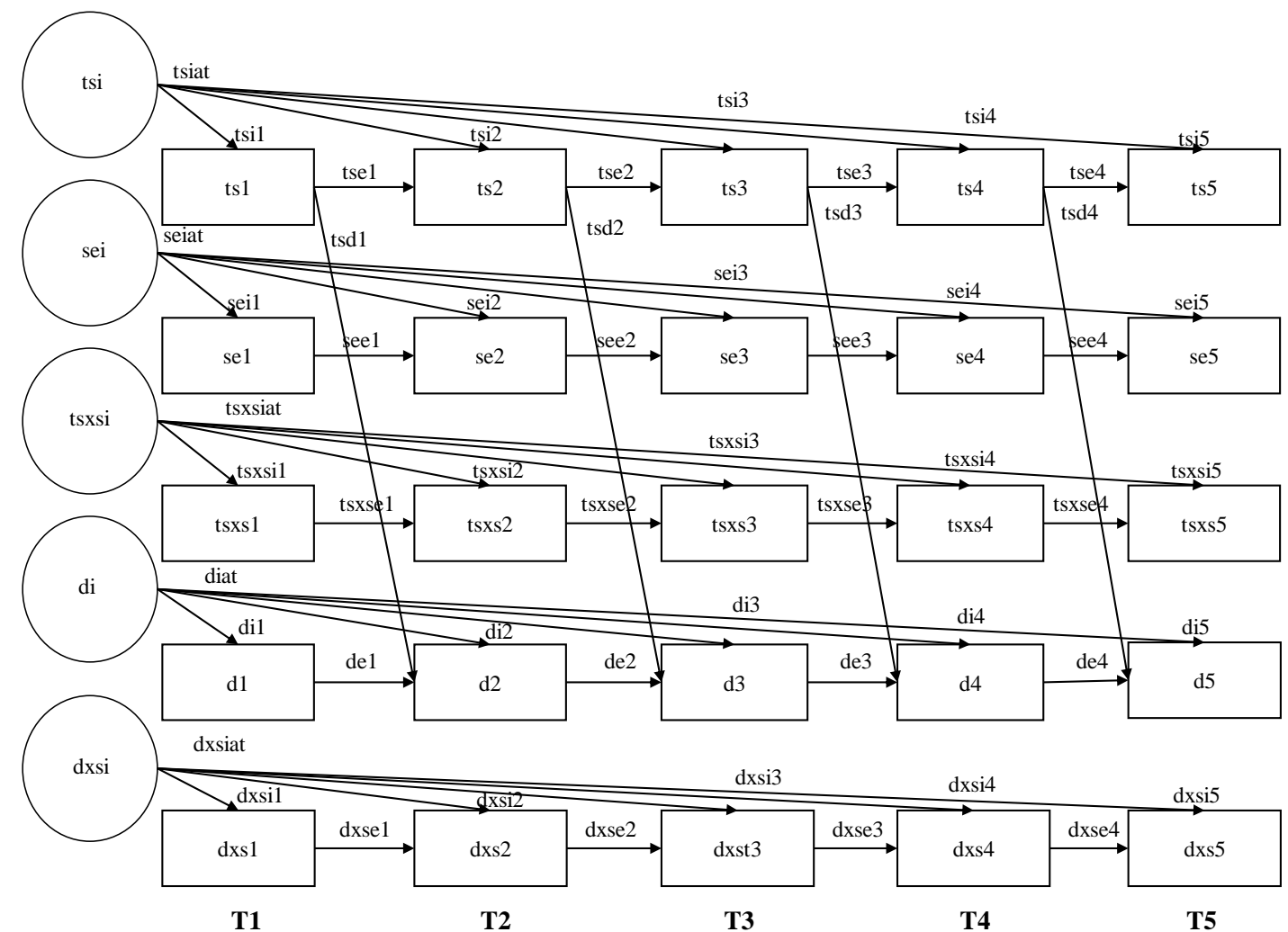

Figure B1. Principle-effect model. For clarity reasons, error terms of the observed variables and correlations between variables measured at the same time are not represented in this graph.

Regression equations for the principle-effect model:

$$
\begin{aligned}
& \text { ts } 5=\text { tsi } 5 * \mathrm{tsi}+\mathrm{tse} 4 * \mathrm{ts} 4+\mathrm{ts} 5 \mathrm{e} \\
& \text { ts } 4=\mathrm{tsi} 4 * \mathrm{tsi}+\mathrm{tse} 3 * \mathrm{ts} 3+\mathrm{ts} 4 \mathrm{e} \\
& \text { ts } 3=\mathrm{tsi} 3 * \mathrm{tsi}+\mathrm{tse} 2 * \mathrm{ts} 2+\mathrm{ts} 3 \mathrm{e} \\
& \text { ts } 2=\mathrm{tsi} 2 * \mathrm{tsi}+\mathrm{tse} 1 * \mathrm{ts} 1+\mathrm{ts} 2 \mathrm{e} \\
& \text { ts } 1=\mathrm{tsi} 1 * \mathrm{tsi}+\mathrm{ts} 1 \mathrm{e} \\
& \operatorname{se} 5=\operatorname{sei} 5 * \operatorname{sei}+\operatorname{see} 4 * \operatorname{se} 4+\operatorname{se} 5 \mathrm{e} \\
& \text { se } 4=\operatorname{sei} 4 * \operatorname{sei}+\operatorname{see} 3 * \operatorname{se} 3+\operatorname{se} 4 \mathrm{e} \\
& \text { se } 3=\operatorname{sei} 3 * \operatorname{sei}+\operatorname{see} 2 * \operatorname{se} 2+\operatorname{se} 3 \mathrm{e} \\
& \text { se } 2=\operatorname{sei} 2 * \operatorname{sei}+\operatorname{see} 1 * \operatorname{se} 1+\operatorname{se} 2 \mathrm{e} \\
& \text { se } 1=\operatorname{sei} 1 * \operatorname{sei}+\operatorname{se} 5 \mathrm{e}
\end{aligned}
$$




$$
\begin{aligned}
& \text { tsxs } 5=\text { tsxsi } 5 * \text { tsxsi }+ \text { tsxse } 4 * \text { tsxs } 4+\text { tsxs } 5 e \\
& \text { tsxs } 4=\text { tsxsi } 4 * \text { tsxsi }+ \text { tsxse } 3 * \operatorname{ts} x s 3+\text { tsxs } 4 \mathrm{e} \\
& \text { tsxs } 3=\text { tsxsi } 3 * \text { tsxsi }+ \text { tsxse } 2 * \operatorname{tsx} 22+\text { tsxs } 3 e \\
& \operatorname{tsxs} 2=\operatorname{tsxsi} 2 * \operatorname{tsxs} i+\operatorname{tsxse} 1 * \operatorname{tsx} s 1+\operatorname{tsxs} 2 \mathrm{e} \\
& \text { tsxs1 = tsxsi } 1 * \text { tsxsi }+ \text { tsxs } 1 \mathrm{e} \\
& \mathrm{d} 5=\mathrm{di} 5 * \mathrm{di}+\mathrm{de} 4 * \mathrm{~d} 4+\mathrm{tsd} 4 * \operatorname{ts} 4+\mathrm{d} 5 \mathrm{e} \\
& \mathrm{d} 4=\mathrm{di} 4 * \mathrm{di}+\mathrm{de} 3 * \mathrm{~d} 3+\mathrm{tsd} 3 * \mathrm{ts} 3+\mathrm{d} 4 \mathrm{e} \\
& \mathrm{d} 3=\mathrm{di} 3 * \mathrm{di}+\mathrm{de} 2 * \mathrm{~d} 2+\mathrm{tsd} 2 * \mathrm{ts} 2+\mathrm{d} 3 \mathrm{e} \\
& \mathrm{d} 2=\mathrm{di} 2 * \mathrm{di}+\mathrm{de} 1 * \mathrm{~d} 1+\operatorname{tsd} 1 * \mathrm{ts} 1+\mathrm{d} 2 \mathrm{e} \\
& \mathrm{d} 1=\mathrm{di} 1 * \mathrm{di}+\mathrm{d} 1 \mathrm{e} \\
& d x s 5=d x s i 5 * d x s i+d x s e 4 * d x s 4+d x s 5 e \\
& d x s 4=d x s i 4 * d x s i+d x s e 3 * d x s 3+d x s 4 e \\
& d x s 3=d x s i 3 * d x s i+d x s e 2 * d x s 2+d x s 3 e \\
& d x s 2=d x s i 2 * d x s i+d x s e 1 * d x s 1+d x s 2 e \\
& \mathrm{dxs} 1=\mathrm{dxsi} 1 * \mathrm{dxsi}+\mathrm{dxs} 1 \mathrm{e}
\end{aligned}
$$




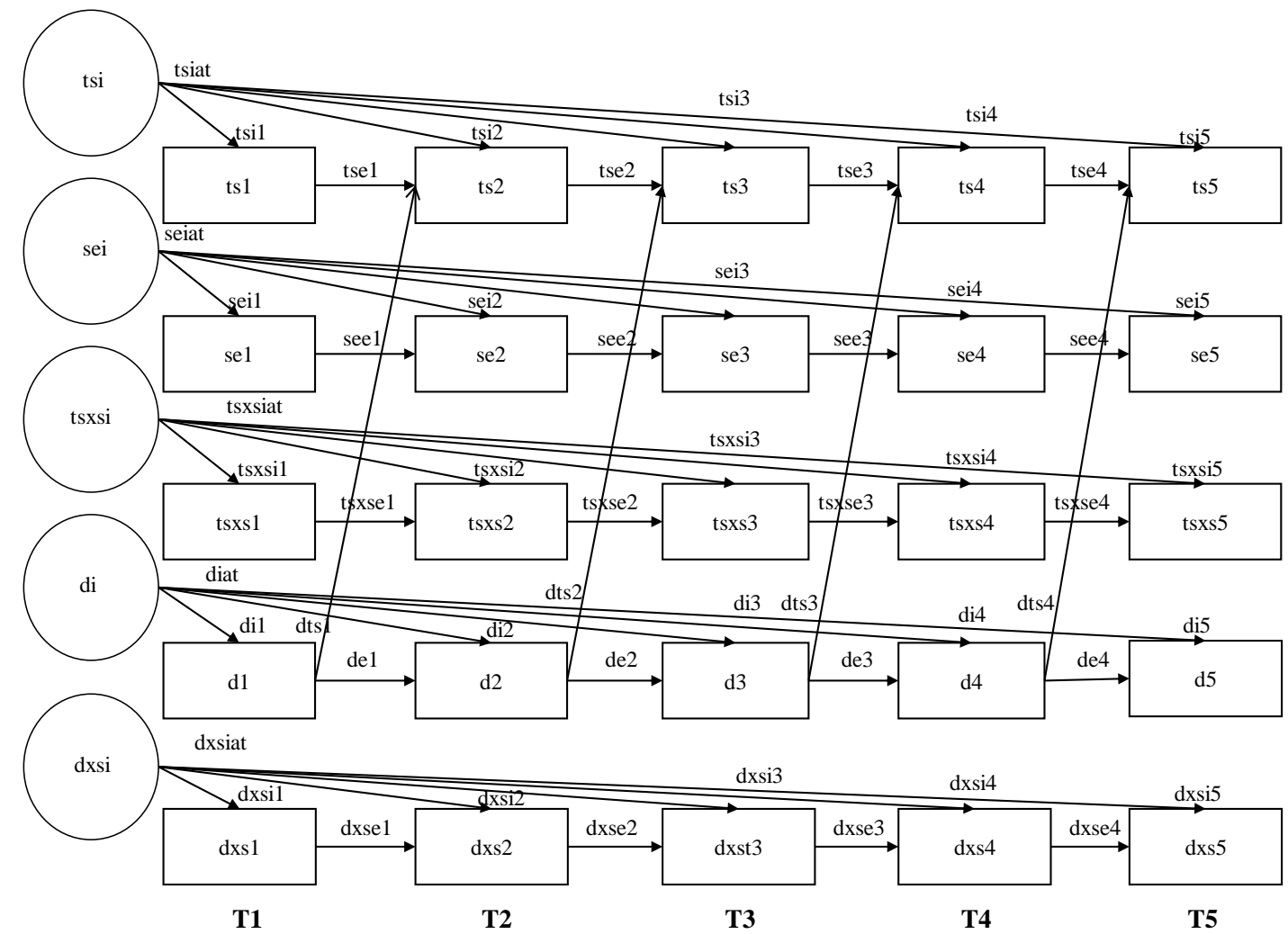

Figure B2. Reversed principle-effect model. For clarity reasons, error terms of the observed variables and correlations between variables measured at the same time are not represented in this graph.

Regression equations for the reversed principle-effect model:

$$
\begin{aligned}
& \text { ts } 5=\text { tsi } 5 * \text { tsi }+ \text { tse } 4 * \operatorname{ts} 4+\text { dts } 4 * d 4+\text { ts } 5 \text { e } \\
& \text { ts } 4=\text { tsi } 4 * \operatorname{tsi}+\text { tse } 3 * \text { ts } 3+d t s 3 * d 3+\text { ts } 4 e \\
& \text { ts } 3=\text { tsi } 3 * t s i+\text { tse } 2 * t s 2+d t s 2 * d 2+\text { ts } 3 e \\
& \text { ts } 2=\text { tsi2 } 2 \text { tsi }+ \text { tse } 1 * t s 1+\mathrm{dts} 1 * \mathrm{~d} 1+\text { ts } 2 \mathrm{e} \\
& \text { ts } 1=\mathrm{tsi} 1 * \mathrm{tsi}+\mathrm{ts} 1 \mathrm{e} \\
& \text { se } 5=\text { sei } 5 * \text { sei }+ \text { see } 4 * \text { se } 4+\text { se } 5 \text { e } \\
& \text { se } 4=\text { sei } 4 * \text { sei }+ \text { see } 3 * \text { se } 3+\text { se } 4 e \\
& \text { se } 3=\text { sei } 3 * \text { sei }+ \text { see } 2 * \operatorname{se} 2+\text { se } 3 e \\
& \text { se } 2=\operatorname{sei} 2 * \text { sei }+ \text { see } 1 * \operatorname{se} 1+\operatorname{se} 2 e \\
& \text { se } 1=\operatorname{sei} 1 * \text { sei }+ \text { se } 5 \mathrm{e}
\end{aligned}
$$




$$
\begin{aligned}
& \text { tsxs } 5=\text { tsxsi } 5^{*} \text { tsxsi }+ \text { tsxse } 4 * \text { tsxs } 4+\text { tsxs } 5 \mathrm{e} \\
& \text { tsxs } 4=\text { tsxsi } 4 * \text { tsxsi }+ \text { tsxse } 3 * \operatorname{tsx} 33+\text { tsxs } 4 \mathrm{e} \\
& \text { tsxs } 3=\text { tsxsi } 3 * \text { tsxsi }+ \text { tsxse } 2 * \text { tsxs } 2+\text { tsxs } 3 e \\
& \operatorname{tsxs} 2=\operatorname{tsxsi} 2 * \operatorname{tsxs} i+\operatorname{tsxse} 1 * \operatorname{tsxs} 1+\operatorname{tsxs} 2 \mathrm{e} \\
& \text { tsxs1 = tsxsi } 1 * \text { tsxsi }+ \text { tsxs } 1 \mathrm{e} \\
& \mathrm{d} 5=\mathrm{di} 5 * \mathrm{di}+\mathrm{de} 4 * \mathrm{~d} 4+\mathrm{d} 5 \mathrm{e} \\
& \mathrm{d} 4=\mathrm{di} 4 * \mathrm{di}+\mathrm{de} 3 * \mathrm{~d} 3+\mathrm{d} 4 \mathrm{e} \\
& \mathrm{d} 3=\mathrm{di} 3 * \mathrm{di}+\mathrm{de} 2 * \mathrm{~d} 2+\mathrm{d} 3 \mathrm{e} \\
& \mathrm{d} 2=\mathrm{di} 2 * \mathrm{di}+\mathrm{de} 1 * \mathrm{~d} 1+\mathrm{d} 2 \mathrm{e} \\
& \mathrm{d} 1=\mathrm{di} 1 * \mathrm{di}+\mathrm{d} 1 \mathrm{e} \\
& d x s 5=d x s i 5 * d x s i+d x s e 4 * d x s 4+d x s 5 e \\
& d x s 4=d x s i 4 * d x s i+d x s e 3 * d x s 3+d x s 4 e \\
& d x s 3=d x s i 3 * d x s i+d x s e 2 * d x s 2+d x s 3 e \\
& d x s 2=d x s i 2 * d x s i+d x s e 1 * d x s 1+d x s 2 e \\
& \mathrm{dxs} 1=\mathrm{dxsi} 1 * \mathrm{dxsi}+\mathrm{dxs} 1 \mathrm{e}
\end{aligned}
$$




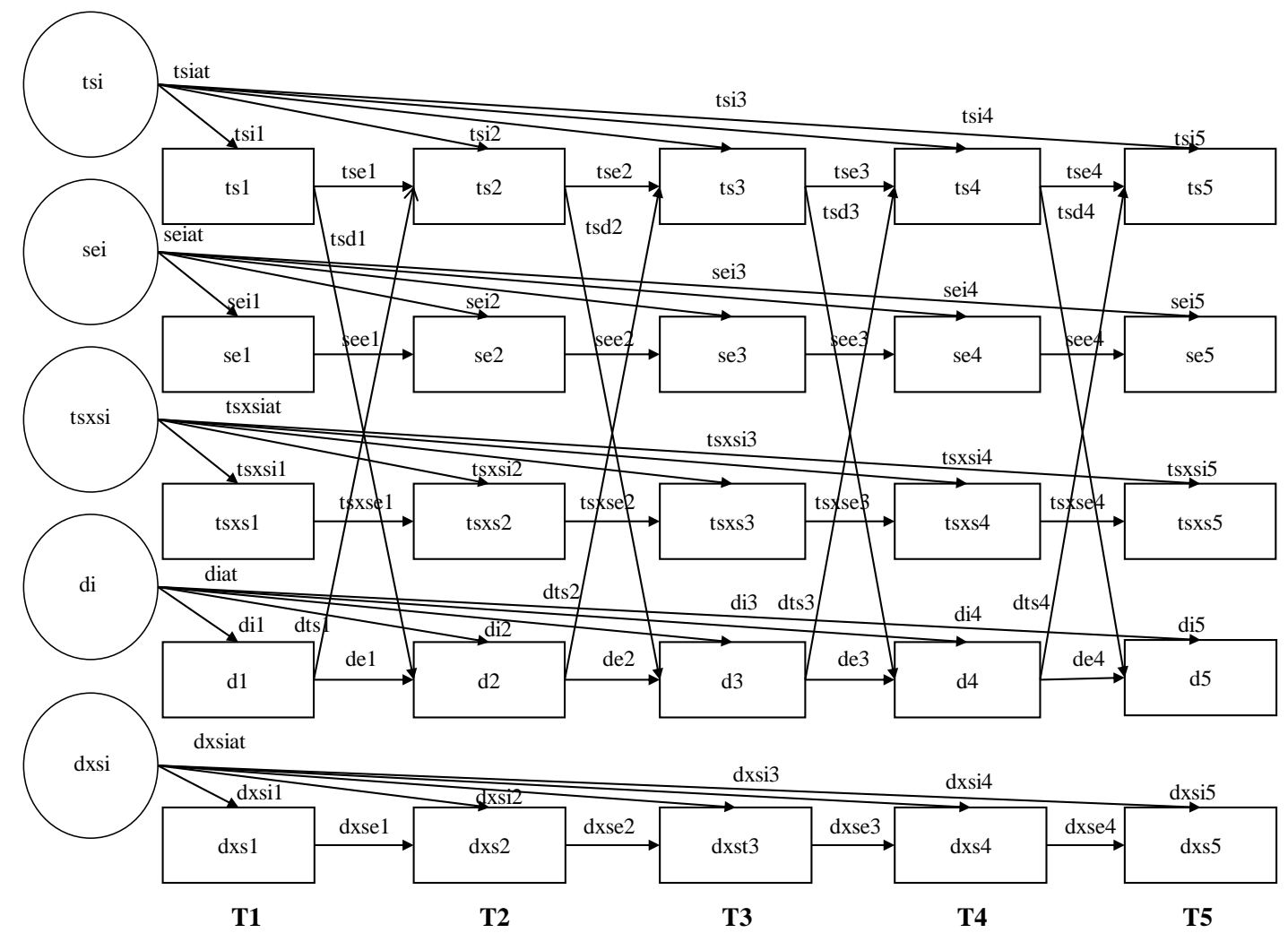

Figure B3. Bidirectional principle-effect model. For clarity reasons, error terms of the observed variables and correlations between variables measured at the same time are not represented in this graph.

Regression equations for the bidirectional principle-effect model:

$$
\begin{aligned}
& \text { ts } 5=\text { tsi } 5 * \text { tsi }+ \text { tse } 4 * \text { ts } 4+\mathrm{dts} 4 * \mathrm{~d} 4+\text { ts } 5 \mathrm{e} \\
& \text { ts } 4=\mathrm{tsi} 4 * \mathrm{tsi}+\mathrm{tse} 3 * \mathrm{ts} 3+\mathrm{dts} 3 * \mathrm{~d} 3+\mathrm{ts} 4 \mathrm{e} \\
& \text { ts } 3=\text { tsi } 3 * t s i+\text { tse } 2 * t s 2+d t s 2 * d 2+\text { ts } 3 e \\
& \text { ts } 2=\text { tsi } 2 * t s i+\text { tse } 1 * t s 1+d t s 1 * d 1+\text { ts } 2 \mathrm{e} \\
& \mathrm{ts} 1=\mathrm{tsi} 1 * \mathrm{tsi}+\mathrm{ts} 1 \mathrm{e} \\
& \text { se } 5=\operatorname{sei} 5 * \text { sei }+\operatorname{see} 4 * \operatorname{se} 4+\operatorname{se} 5 \mathrm{e} \\
& \text { se } 4=\operatorname{sei} 4 * \text { sei }+ \text { see } 3 * \operatorname{se} 3+\operatorname{se} 4 \mathrm{e} \\
& \operatorname{se} 3=\operatorname{sei} 3 * \operatorname{sei}+\operatorname{see} 2 * \operatorname{se} 2+\operatorname{se} 3 e \\
& \text { se } 2=\operatorname{sei} 2 * \text { sei }+\operatorname{see} 1 * \operatorname{se} 1+\operatorname{se} 2 \mathrm{e} \\
& \operatorname{se} 1=\operatorname{sei} 1 * \operatorname{sei}+\operatorname{se} 5 \mathrm{e}
\end{aligned}
$$




$$
\begin{aligned}
& \text { tsxs } 5=\text { tsxsi } 5 * \text { tsxsi }+ \text { tsxse } 4 * \text { tsxs } 4+\text { tsxs } 5 e \\
& \text { tsxs } 4=\text { tsxsi } 4 * \text { tsxsi }+ \text { tsxse } 3 * \operatorname{ts} x s 3+\text { tsxs } 4 \mathrm{e} \\
& \text { tsxs } 3=\text { tsxsi } 3 * \text { tsxsi }+ \text { tsxse } 2 * \operatorname{tsx} 22+\text { tsxs } 3 e \\
& \operatorname{tsxs} 2=\operatorname{tsxsi} 2 * \operatorname{tsxs} i+\operatorname{tsxse} 1 * \operatorname{tsx} s 1+\operatorname{tsxs} 2 \mathrm{e} \\
& \text { tsxs1 = tsxsi } 1 * \text { tsxsi }+ \text { tsxs } 1 \mathrm{e} \\
& \mathrm{d} 5=\mathrm{di} 5 * \mathrm{di}+\mathrm{de} 4 * \mathrm{~d} 4+\mathrm{tsd} 4 * \operatorname{ts} 4+\mathrm{d} 5 \mathrm{e} \\
& \mathrm{d} 4=\mathrm{di} 4 * \mathrm{di}+\mathrm{de} 3 * \mathrm{~d} 3+\mathrm{tsd} 3 * \mathrm{ts} 3+\mathrm{d} 4 \mathrm{e} \\
& \mathrm{d} 3=\mathrm{di} 3 * \mathrm{di}+\mathrm{de} 2 * \mathrm{~d} 2+\mathrm{tsd} 2 * \mathrm{ts} 2+\mathrm{d} 3 \mathrm{e} \\
& \mathrm{d} 2=\mathrm{di} 2 * \mathrm{di}+\mathrm{de} 1 * \mathrm{~d} 1+\operatorname{tsd} 1 * \mathrm{ts} 1+\mathrm{d} 2 \mathrm{e} \\
& \mathrm{d} 1=\mathrm{di} 1 * \mathrm{di}+\mathrm{d} 1 \mathrm{e} \\
& d x s 5=d x s i 5 * d x s i+d x s e 4 * d x s 4+d x s 5 e \\
& d x s 4=d x s i 4 * d x s i+d x s e 3 * d x s 3+d x s 4 e \\
& d x s 3=d x s i 3 * d x s i+d x s e 2 * d x s 2+d x s 3 e \\
& d x s 2=d x s i 2 * d x s i+d x s e 1 * d x s 1+d x s 2 e \\
& \mathrm{dxs} 1=\mathrm{dxsi} 1 * \mathrm{dxsi}+\mathrm{dxs} 1 \mathrm{e}
\end{aligned}
$$




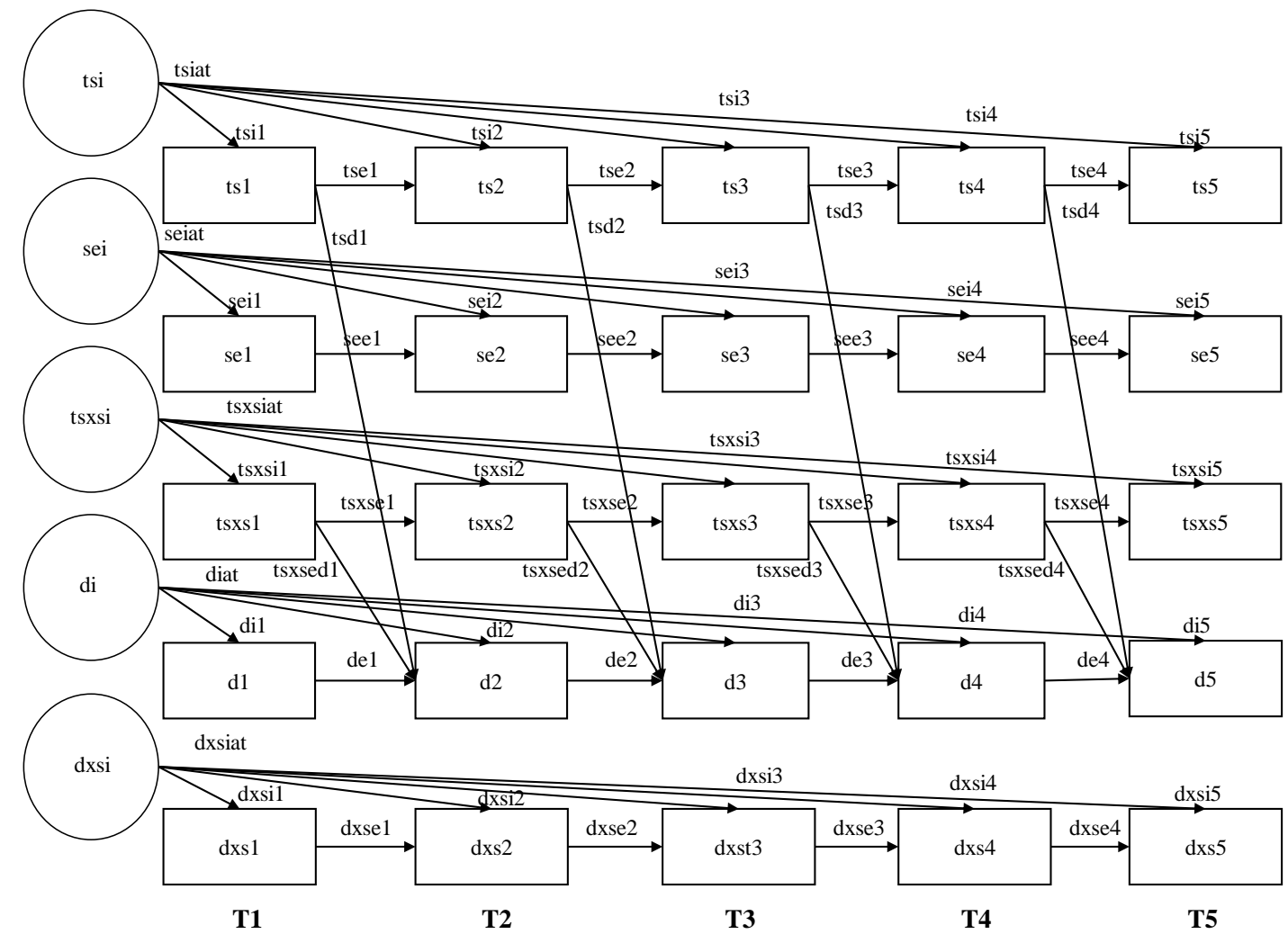

Figure B4. Stress-buffer model. For clarity reasons, error terms of the observed variables and correlations between variables measured at the same time are not represented in this graph.

Regression equations for the stress-buffer model:

$$
\begin{aligned}
& \text { ts } 5=\text { tsi } 5 * \text { tsi }+ \text { tse } 4 * \text { ts } 4+\text { ts } 5 \mathrm{e} \\
& \text { ts } 4=\text { tsi } 4 * \text { tsi }+ \text { tse } 3 * \text { ts } 3+\text { ts } 4 \mathrm{e} \\
& \text { ts } 3=\text { tsi } 3 * t s i+t s e 2 * t s 2+\text { ts } 3 e \\
& \text { ts } 2=\text { tsi } 2 * t s i+\text { tse } 1 * t s 1+\text { ts } 2 \mathrm{e} \\
& \text { ts } 1=\text { tsi } 1 * \text { tsi }+ \text { ts } 1 \mathrm{e} \\
& \text { se } 5=\text { sei } 5 * \text { sei }+ \text { see } 4 * \text { se } 4+\text { se } 5 \text { e } \\
& \text { se } 4=\operatorname{sei} 4 * \text { sei }+ \text { see } 3 * \text { se } 3+\text { se } 4 e \\
& \text { se } 3=\text { sei } 3 * \text { sei }+ \text { see } 2 * \operatorname{se} 2+\text { se } 3 e \\
& \text { se } 2=\text { sei } 2 * \text { sei }+ \text { see } 1 * \operatorname{se} 1+\text { se } 2 \mathrm{e} \\
& \text { se } 1=\operatorname{sei} 1 * \text { sei }+ \text { se } 5 \mathrm{e}
\end{aligned}
$$




$$
\begin{aligned}
& \text { tsxs } 5=\text { tsxsi } 5 * \text { tsxsi }+ \text { tsxse } 4 * \operatorname{tsxs} 4+\text { tsxs } 5 \mathrm{e} \\
& \text { tsxs } 4=\text { tsxsi } 4 * \text { tsxsi }+ \text { tsxse } 3 * \text { tsxs } 3+\text { tsxs } 4 \mathrm{e} \\
& \text { tsxs } 3=\text { tsxsi } 3 * \text { tsxsi }+ \text { tsxse } 2 * \operatorname{tsx} 22+\operatorname{tsxs} 3 e \\
& \text { tsxs } 2=\text { tsxsi } 2 * \text { tsxsi }+ \text { tsxse } 1 * \text { tsxs } 1+\text { tsxs } 2 \mathrm{e} \\
& \text { tsxs1 = tsxsi } 1 * \text { tsxsi }+ \text { tsxs } 1 \mathrm{e} \\
& \mathrm{d} 5=\mathrm{di} 5 * \mathrm{di}+\mathrm{de} 4 * \mathrm{~d} 4+\mathrm{tsd} 4 * \mathrm{ts} 4+\mathrm{tsxsed} 4 * \operatorname{tsxs} 4+\mathrm{d} 5 \mathrm{e} \\
& \mathrm{d} 4=\mathrm{di} 4 * \mathrm{di}+\mathrm{de} 3 * \mathrm{~d} 3+\mathrm{tsd} 3 * \mathrm{ts} 3+\mathrm{tsxsed} 3 * \operatorname{tsxs} 3+\mathrm{d} 4 \mathrm{e} \\
& \mathrm{d} 3=\mathrm{di} 3 * \mathrm{di}+\mathrm{de} 2 * \mathrm{~d} 2+\mathrm{tsd} 2 * \mathrm{ts} 2+\operatorname{tsxsed} 2 * \operatorname{tsx} 2+\mathrm{d} 3 e \\
& \mathrm{~d} 2=\mathrm{di} 2 * \mathrm{di}+\mathrm{de} 1 * \mathrm{~d} 1+\mathrm{tsd} 1 * \mathrm{ts} 1+\mathrm{tsxsed} 1 * \operatorname{tsxs} 1+\mathrm{d} 2 \mathrm{e} \\
& \mathrm{d} 1=\mathrm{di} 1 * \mathrm{di}+\mathrm{d} 1 \mathrm{e} \\
& \mathrm{dxs} 5=\mathrm{dxsi} 5 * \mathrm{dxsi}+\mathrm{dxse} 4 * \mathrm{dxs} 4+\mathrm{dxs} 5 \mathrm{e} \\
& \mathrm{dxs} 4=\mathrm{dxsi} 4 * d x s i+d x \operatorname{se} 3 * \mathrm{dxs} 3+\mathrm{dxs} 4 \mathrm{e} \\
& d x s 3=d x s i 3 * d x s i+d x s e 2 * d x s 2+d x s 3 e \\
& \mathrm{dxs} 2=\mathrm{dxsi} 2 * \mathrm{dxsi}+\mathrm{dxse} 1 * \mathrm{dxs} 1+\mathrm{dxs} 2 \mathrm{e} \\
& \mathrm{dxs} 1=\mathrm{dxsi} 1 * \mathrm{dxsi}+\mathrm{dxs} 1 \mathrm{e}
\end{aligned}
$$




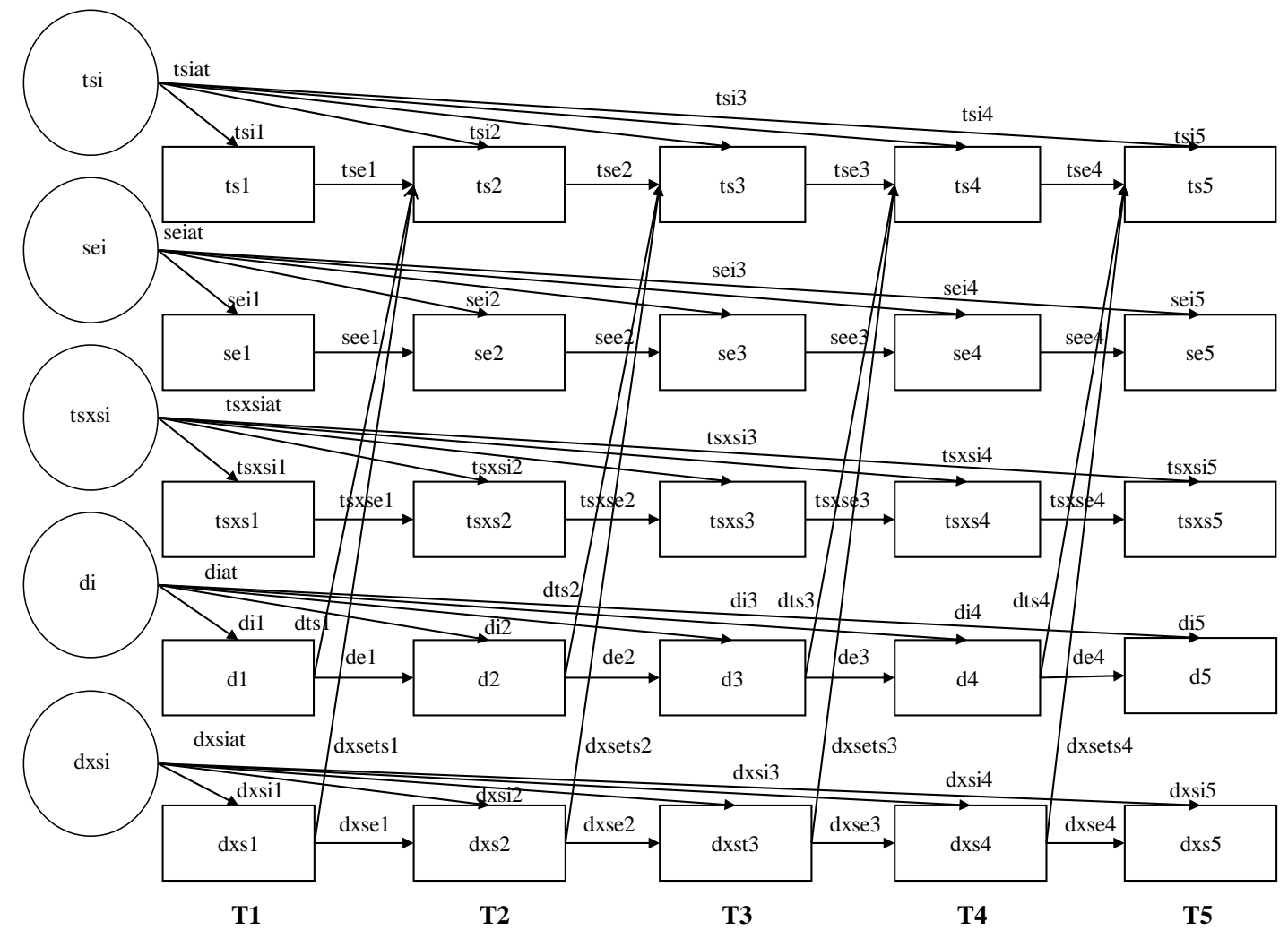

Figure B5. Reversed stress-buffer model. For clarity reasons, error terms of the observed variables and correlations between variables measured at the same time are not represented in this graph.

Regression equations for the reversed stress-buffer model:

$$
\begin{aligned}
& \text { ts } 5=\text { tsi } 5 * \text { tsi }+ \text { tse } 4 * \text { ts } 4+\text { dts } 4 * d 4+\text { dxsets } 4 * d x s 4+\text { ts } 5 e \\
& \text { ts } 4=\text { tsi } 4 * \text { tsi }+ \text { tse } 3 * \text { ts } 3+d t s 3 * d 3+d x \operatorname{sets} 3 * d x s 3+\text { ts } 4 e \\
& \text { ts } 3=\text { tsi } 3 * t s i+\text { tse } 2 * t s 2+d t s 2 * d 2+\text { dxsets } 2 * d x s 2+\text { ts } 3 e \\
& \text { ts } 2=\text { tsi } 2 * t s i+\text { tse } 1 * t s 1+d t s 1 * d 1+d x \operatorname{sets} 1 * d x s 1+\text { ts } 2 e \\
& \text { ts } 1=\text { tsi } 1 * \text { tsi }+ \text { ts } 1 \mathrm{e} \\
& \text { se } 5=\text { sei } 5 * \text { sei }+ \text { see } 4 * \text { se } 4+\text { se } 5 \text { e } \\
& \text { se } 4=\operatorname{sei} 4 * \text { sei }+ \text { see } 3 * \operatorname{se} 3+\text { se } 4 e \\
& \text { se } 3=\text { sei } 3 * \text { sei }+ \text { see } 2 * \operatorname{se} 2+\operatorname{se} 3 e \\
& \operatorname{se} 2=\operatorname{sei} 2 * \operatorname{sei}+\operatorname{see} 1 * \operatorname{se} 1+\operatorname{se} 2 \mathrm{e} \\
& \text { se } 1=\operatorname{sei} 1 * \text { sei }+ \text { se } 5 \mathrm{e}
\end{aligned}
$$




$$
\begin{aligned}
& \text { tsxs } 5=\text { tsxsi } 5 * \text { tsxsi }+ \text { tsxse } 4 * \text { tsxs } 4+\text { tsxs } 5 e \\
& \text { tsxs } 4=\text { tsxsi } 4 * \text { tsxsi }+ \text { tsxse } 3 * \operatorname{ts} x s 3+\text { tsxs } 4 \mathrm{e} \\
& \text { tsxs } 3=\text { tsxsi } 3 * \text { tsxsi }+ \text { tsxse } 2 * \operatorname{tsx} 22+\text { tsxs } 3 e \\
& \text { tsxs } 2=\text { tsxsi } 2 * \text { tsxsi }+ \text { tsxse } 1 * \text { tsxs } 1+\text { tsxs } 2 \mathrm{e} \\
& \text { tsxs1 = tsxsi } 1 * \text { tsxsi }+ \text { tsxs } 1 \mathrm{e} \\
& \mathrm{d} 5=\mathrm{di} 5 * \mathrm{di}+\mathrm{de} 4 * \mathrm{~d} 4+\mathrm{d} 5 \mathrm{e} \\
& \mathrm{d} 4=\mathrm{di} 4 * \mathrm{di}+\mathrm{de} 3 * \mathrm{~d} 3+\mathrm{d} 4 \mathrm{e} \\
& \mathrm{d} 3=\mathrm{di} 3 * \mathrm{di}+\mathrm{de} 2 * \mathrm{~d} 2+\mathrm{d} 3 \mathrm{e} \\
& \mathrm{d} 2=\mathrm{di} 2 * \mathrm{di}+\mathrm{de} 1 * \mathrm{~d} 1+\mathrm{d} 2 \mathrm{e} \\
& \mathrm{d} 1=\mathrm{di} 1 * \mathrm{di}+\mathrm{d} 1 \mathrm{e} \\
& d x s 5=d x s i 5 * d x s i+d x s e 4 * d x s 4+d x s 5 e \\
& d x s 4=d x s i 4 * d x s i+d x s e 3 * d x s 3+d x s 4 e \\
& d x s 3=d x s i 3 * d x s i+d x s e 2 * d x s 2+d x s 3 e \\
& d x s 2=d x s i 2 * d x s i+d x s e 1 * d x s 1+d x s 2 e \\
& \mathrm{dxs} 1=\mathrm{dxsi} 1 * \mathrm{dxsi}+\mathrm{dxs} 1 \mathrm{e}
\end{aligned}
$$




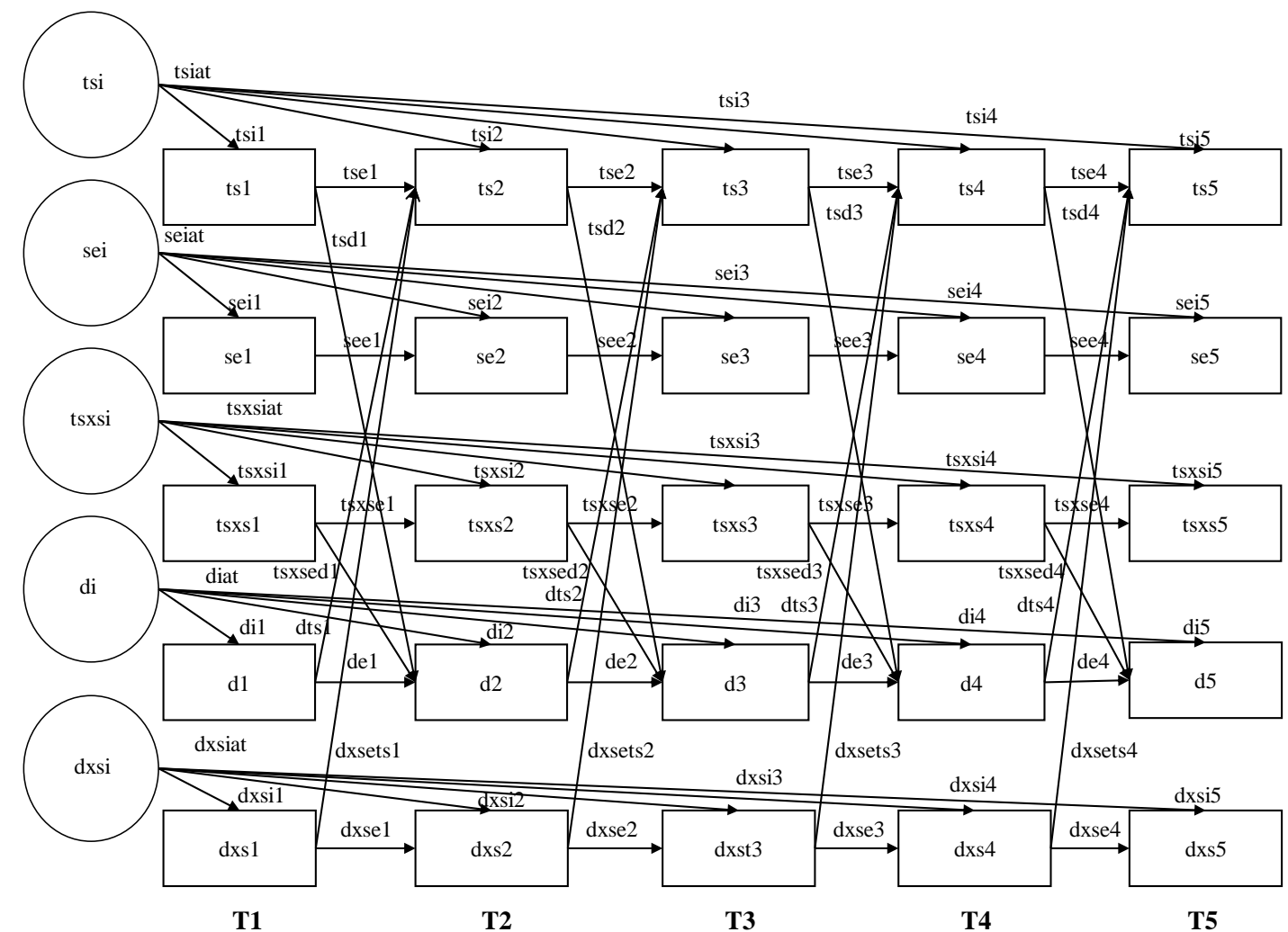

Figure B6. Bidirectional stress-buffer model. For clarity reasons, error terms of the observed variables and correlations between variables measured at the same time are not represented in this graph.

Regression equations for the bidirectional stress-buffer model:

$$
\begin{aligned}
& \text { ts } 5=\text { tsi } 5 * \text { tsi }+ \text { tse } 4 * \text { ts } 4+\text { dts } 4 * d 4+\text { dxsets } 4 * d x s 4+\text { ts } 5 e \\
& \text { ts } 4=\text { tsi } 4 * \text { tsi }+ \text { tse } 3 * t s 3+d t s 3 * d 3+d x \operatorname{sets} 3 * d x s 3+\text { ts } 4 e \\
& \text { ts } 3=\text { tsi } 3 * t s i+\text { tse } 2 * t s 2+d t s 2 * d 2+d x \operatorname{sets} 2 * d x s 2+\text { ts } 3 e \\
& \text { ts } 2=\text { tsi } 2 * \operatorname{tsi}+\operatorname{tse} 1 * \operatorname{ts} 1+\mathrm{dts} 1 * \mathrm{~d} 1+\mathrm{dxsets} 1 * \mathrm{dxs} 1+\mathrm{ts} 2 \mathrm{e} \\
& \text { ts } 1=\text { tsi } 1 * \text { tsi }+ \text { ts } 1 \mathrm{e} \\
& \text { se } 5=\text { sei } 5 * \text { sei }+ \text { see } 4 * \text { se } 4+\text { se } 5 \text { e } \\
& \text { se } 4=\operatorname{sei} 4 * \text { sei }+ \text { see } 3 * \operatorname{se} 3+\text { se } 4 e \\
& \text { se } 3=\text { sei } 3 * \text { sei }+ \text { see } 2 * \operatorname{se} 2+\operatorname{se} 3 e \\
& \operatorname{se} 2=\operatorname{sei} 2 * \operatorname{sei}+\operatorname{see} 1 * \operatorname{se} 1+\operatorname{se} 2 \mathrm{e} \\
& \text { se } 1=\operatorname{sei} 1 * \text { sei }+ \text { se } 5 \mathrm{e}
\end{aligned}
$$




$$
\begin{aligned}
& \text { tsxs } 5=\text { tsxsi } 5 * \text { tsxsi }+ \text { tsxse } 4 * \operatorname{tsxs} 4+\text { tsxs } 5 \mathrm{e} \\
& \text { tsxs } 4=\text { tsxsi } 4 * \text { tsxsi }+ \text { tsxse } 3 * \operatorname{ts} x s 3+\text { tsxs } 4 \mathrm{e} \\
& \text { tsxs } 3=\text { tsxsi } 3 * \text { tsxsi }+ \text { tsxse } 2 * \operatorname{tsx} 22+\operatorname{tsxs} 3 e \\
& \text { tsxs } 2=\text { tsxsi } 2 * \text { tsxsi }+ \text { tsxse } 1 * \text { tsxs } 1+\text { tsxs } 2 \mathrm{e} \\
& \text { tsxs1 = tsxsi } 1 * \text { tsxsi }+ \text { tsxs } 1 \mathrm{e} \\
& \mathrm{d} 5=\mathrm{di} 5 * \mathrm{di}+\mathrm{de} 4 * \mathrm{~d} 4+\mathrm{tsd} 4 * \mathrm{ts} 4+\mathrm{tsxsed} 4 * \operatorname{tsxs} 4+\mathrm{d} 5 \mathrm{e} \\
& \mathrm{d} 4=\mathrm{di} 4 * \mathrm{di}+\mathrm{de} 3 * \mathrm{~d} 3+\mathrm{tsd} 3 * \mathrm{ts} 3+\mathrm{tsxsed} 3 * \operatorname{tsxs} 3+\mathrm{d} 4 \mathrm{e} \\
& \mathrm{d} 3=\mathrm{di} 3 * \mathrm{di}+\mathrm{de} 2 * \mathrm{~d} 2+\mathrm{tsd} 2 * \mathrm{ts} 2+\operatorname{tsxsed} 2 * \operatorname{tsx} 2+\mathrm{d} 3 e \\
& \mathrm{~d} 2=\mathrm{di} 2 * \mathrm{di}+\mathrm{de} 1 * \mathrm{~d} 1+\mathrm{tsd} 1 * \mathrm{ts} 1+\mathrm{tsxsed} 1 * \operatorname{tsxs} 1+\mathrm{d} 2 \mathrm{e} \\
& \mathrm{d} 1=\mathrm{di} 1 * \mathrm{di}+\mathrm{d} 1 \mathrm{e} \\
& \mathrm{dxs} 5=\mathrm{dxsi} 5 * \mathrm{dxsi}+\mathrm{dxse} 4 * \mathrm{dxs} 4+\mathrm{dxs} 5 \mathrm{e} \\
& \mathrm{dxs} 4=\mathrm{dxsi} 4 * d x s i+d x \operatorname{se} 3 * \mathrm{dxs} 3+\mathrm{dxs} 4 \mathrm{e} \\
& d x s 3=d x s i 3 * d x s i+d x s e 2 * d x s 2+d x s 3 e \\
& \mathrm{dxs} 2=\mathrm{dxsi} 2 * \mathrm{dxsi}+\mathrm{dxse} 1 * \mathrm{dxs} 1+\mathrm{dxs} 2 \mathrm{e} \\
& \mathrm{dxs} 1=\mathrm{dxsi} 1 * \mathrm{dxsi}+\mathrm{dxs} 1 \mathrm{e}
\end{aligned}
$$


Definitions of all notations in all models:

tsi $=$ teacher support intercept

ts $1=$ teacher support at grade 8

ts $2=$ teacher support at grade 9

ts $3=$ teacher support at grade 10

ts $4=$ teacher support at grade 11

ts $5=$ teacher support at grade 12

ts1e $=$ teacher support error at grade 8

ts $2 \mathrm{e}=$ teacher support error at grade 9

ts $3 \mathrm{e}=$ teacher support error at grade 10

ts $4 \mathrm{e}=$ teacher support error at grade 11

ts $5 \mathrm{e}=$ teacher support error at grade 12

tsi1 $=$ path from teacher support intercept to teacher support at grade 8

tsi $2=$ path from teacher support intercept to teacher support at grade 9

tsi3 = path from teacher support intercept to teacher support at grade 10

tsi4 $=$ path from teacher support intercept to teacher support at grade 11

tsi5 $=$ path from teacher support intercept to teacher support at grade 12

tse $1=$ path from teacher support at grade 8 to teacher support at grade 9

tse $2=$ path from teacher support at grade 9 to teacher support at grade 10

tse $3=$ path from teacher support at grade 10 to teacher support at grade 11

tse $4=$ path from teacher support at grade 11 to teacher support at grade 12

sei $=$ stressful events intercept

se $1=$ stressful events at grade 8 
se $2=$ stressful events at grade 9

se $3=$ stressful events at grade 10

se $4=$ stressful events at grade 11

se $5=$ stressful events at grade 12

se $1 \mathrm{e}=$ stressful events error at grade 8

se $2 \mathrm{e}=$ stressful events error at grade 9

se $3 e=$ stressful events error at grade 10

see $4 \mathrm{e}=$ stressful events error at grade 11

se $5 \mathrm{e}=$ stressful events error at grade 12

seil $=$ path from stressful events intercept to stressful events at grade 8

sei2 $=$ path from stressful events intercept to stressful events at grade 9

sei3 $=$ path from stressful events intercept to stressful events at grade 10

sei4 $=$ path from stressful events intercept to stressful events at grade 11

sei5 $=$ path from stressful events intercept to stressful events at grade 12

see $1=$ path from stressful events at grade 8 to stressful events at grade 9

see $2=$ path from stressful events at grade 9 to stressful events at grade 10

see $3=$ path from stressful events at grade 10 to stressful events at grade 11

see $4=$ path from stressful events at grade 11 to stressful events at grade 12

tsxsi $=$ teacher support $\mathrm{x}$ stress event intercept

tsxs $1=$ teacher support $\mathrm{x}$ stressful events at grade 8

tsxs $2=$ teacher support $\mathrm{x}$ stressful events at grade 9

tsxs3 = teacher support $\mathrm{x}$ stressful events at grade 10

tsxs4 = teacher support $\mathrm{x}$ stressful events at grade 11 
tsxs5 $=$ teacher support $\mathrm{x}$ stressful events at grade 12

tsxs1e $=$ teacher support $\mathrm{x}$ stressful events error at grade 8

tsxs $2 \mathrm{e}=$ teacher support $\mathrm{x}$ stressful events error at grade 9

tsxs $3 \mathrm{e}=$ teacher support $\mathrm{x}$ stressful events error at grade 10

tsxs4e $=$ teacher support $\mathrm{x}$ stressful events error at grade 11

tsxs $5 \mathrm{e}=$ teacher support $\mathrm{x}$ stressful events error at grade 12

tsxsi1 = path from teacher support $\mathrm{x}$ stress event intercept to teacher support $\mathrm{x}$ stressful

events at grade 8

tsxsi $2=$ path from teacher support $\mathrm{x}$ stress event intercept to teacher support $\mathrm{x}$ stressful events at grade 9

tsxsi3 = path from teacher support $\mathrm{x}$ stress event intercept to teacher support $\mathrm{x}$ stressful events at grade 10

tsxsi4 $=$ path from teacher support $\mathrm{x}$ stress event intercept to teacher support $\mathrm{x}$ stressful events at grade 11

tsxsi5 $=$ path from teacher support $\mathrm{x}$ stress event intercept to teacher support $\mathrm{x}$ stressful events at grade 12

tsxse $1=$ path from teacher support $\mathrm{x}$ stressful events at grade 8 to teacher support $\mathrm{x}$ stressful events at grade 9

tsxse $2=$ path from teacher support $\mathrm{x}$ stressful events at grade 9 to teacher support $\mathrm{x}$ stressful events at grade 10

tsxse $3=$ path from teacher support $\mathrm{x}$ stressful events at grade 10 to teacher support $\mathrm{x}$ stressful events at grade 11 
tsxse $4=$ path from teacher support $\mathrm{x}$ stressful events at grade 11 to teacher support $\mathrm{x}$ stressful events at grade 12

$\mathrm{di}=$ depression intercept

$\mathrm{d} 1=$ depression at grade 8

$\mathrm{d} 2=$ depression at grade 9

$\mathrm{d} 3=$ depression at grade 10

$\mathrm{d} 4=$ depression at grade 11

d5 = depression at grade 12

$\mathrm{d} 1 \mathrm{e}=$ depression error at grade 8

$\mathrm{d} 2 \mathrm{e}=$ depression error at grade 9

$\mathrm{d} 3 \mathrm{e}=$ depression error at grade 10

$\mathrm{d} 4 \mathrm{e}=$ depression error at grade 11

$\mathrm{d} 5 \mathrm{e}=$ depression error at grade 12

di1 $=$ path from depression intercept to depression at grade 8

$\operatorname{di} 2=$ path from depression intercept to depression at grade 9

di3 $=$ path from depression intercept to depression at grade 10

$\mathrm{di} 4=$ path from depression intercept to depression at grade 11

$\operatorname{di} 5=$ path from depression intercept to depression at grade 12

de $1=$ path from depression at grade 8 to depression at grade 9

de $2=$ path from depression at grade 9 to depression at grade 10

de $3=$ path from depression at grade 10 to depression at grade 11

de4 = path from depression at grade 11 to depression at grade 12

$\mathrm{dxsi}=$ depression $\mathrm{x}$ stress event intercept 
$\mathrm{dxs} 1=$ depression $\mathrm{x}$ stressful events at grade 8

dxs2 $=$ depression $x$ stressful events at grade 9

$\mathrm{dxs} 3=$ depression $\mathrm{x}$ stressful events at grade 10

dxs4 = depression $\mathrm{x}$ stressful events at grade 11

$\mathrm{dxs} 5=$ depression $\mathrm{x}$ stressful events at grade 12

$\mathrm{dxs} 1 \mathrm{e}=$ depression $\mathrm{x}$ stressful events error at grade 8

$\mathrm{dxs} 2 \mathrm{e}=$ depression $\mathrm{x}$ stressful events error at grade 9

$\mathrm{dxs} 3 \mathrm{e}=$ depression $\mathrm{x}$ stressful events error at grade 10

$\mathrm{dxs} 4 \mathrm{e}=$ depression $\mathrm{x}$ stressful events error at grade 11

$\mathrm{dxs} 5 \mathrm{e}=$ depression $\mathrm{x}$ stressful events error at grade 12

$\mathrm{dxsi1}=$ path from depression $\mathrm{x}$ stress event intercept to depression $\mathrm{x}$ stressful events at grade 8

$\mathrm{dxsi} 2=$ path from depression $\mathrm{x}$ stress event intercept to depression $\mathrm{x}$ stressful events at grade 9

$\mathrm{dxsi} 3=$ path from depression $\mathrm{x}$ stress event intercept to depression $\mathrm{x}$ stressful events at grade 10

$\mathrm{dxsi} 4=$ path from depression $\mathrm{x}$ stress event intercept to depression $\mathrm{x}$ stressful events at grade 11

dxsi5 = path from depression $\mathrm{x}$ stress event intercept to depression $\mathrm{x}$ stressful events at grade 12

$\mathrm{dxse} 1=$ path from depression $\mathrm{x}$ stressful events at grade 8 to depression $\mathrm{x}$ stressful events at grade 9 
dxse 2 = path from depression $x$ stressful events at grade 9 to depression $x$ stressful events at grade 10

dxse 3 = path from depression $x$ stressful events at grade 10 to depression $x$ stressful events at grade 11

dxse $4=$ path from depression $x$ stressful events at grade 11 to depression $x$ stressful events at grade 12

tsd $1=$ path from teacher support at grade 8 to depression at grade 9 tsd $2=$ path from teacher support at grade 9 to depression at grade 10 tsd $3=$ path from teacher support at grade 10 to depression at grade 11 tsd $4=$ path from teacher support at grade 11 to depression at grade 12 dts $1=$ path from depression at grade 8 to teacher support at grade 9 dts $2=$ path from depression at grade 9 to teacher support at grade 10 dts 3 = path from depression at grade 10 to teacher support at grade 11 dts $4=$ path from depression at grade 11 to teacher support at grade 12 tsxesd $1=$ path from teacher support $\mathrm{x}$ stressful events at grade 8 to depression at grade 9 tsxesd $2=$ path from teacher support $\mathrm{x}$ stressful events at grade 9 to depression at grade 10 tsxesd 3 = path from teacher support $\mathrm{x}$ stressful events at grade 10 to depression at grade 11 tsxesd4 = path from teacher support $\mathrm{x}$ stressful events at grade 11 to depression at grade 12

dxsets $1=$ path from depression $\mathrm{x}$ stressful events at grade 8 to teacher support at grade 9 dxsets $2=$ path from depression x stressful events at grade 9 to teacher support at grade 10 
dxsets 3 = path from depression $x$ stressful events at grade 10 to teacher support at grade 11

dxsets $4=$ path from depression $\mathrm{x}$ stressful events at grade 11 to teacher support at grade 12 


\section{Supplement C}

Considering the dropout rate of $46.64 \%$ of the baseline sample, the above reported analyses were also calculated with imputed data. For this purpose, multiple imputation using Bayesian estimation was used where missing data are estimated by "linking observed and missing data to the model parameters" (p. 318, Sinharay, Stern, \& Russell, 2001). The findings with imputed data were virtually identical to those from which the data of students that dropped out were deleted. This is not surprising because the assumptions of imputation calculations rely on the existing values from the original data set. These assumptions likely reduce the reliability/validity of the missing values because they are missing in a systematic, nonrandom manner. Therefore, results based on imputed data are not reported in this article but can be requested from the first author.

As eight of the participating 50 schools were not co-educational it is possible that school and sex were confounded. Thus, the above reported analyses were calculated only with girls $(n=1,779)$ and boys $(n=1,833)$ in mixed gender schools. The findings with only students in mixed gender schools confirmed the findings with all students. While results based only on students in mixed gender schools are not reported in this article, they can be requested from the first author.

Further, considering the fact that the data of the beyondblue sample were collected as part of a prevention study, the intervention condition was tested as a potential moderator using a multiple group analysis. This multiple group analysis comparing students in the prevention condition $(n=2,265)$ with whose in the control condition $(n=$ 2,076) indicated statistical but not practical variance of the stress-buffer model across both conditions $\left[\chi^{2}\right.$ unconstrained $(464)=1520.58, p<.001$, CFI (0.980), RMSEA (0.023); $\chi^{2}$ 
fully constrained $(609)=2933.28, p<.001, \mathrm{CFI}(0.976), \operatorname{RMSEA}(0.030) ; \Delta \chi^{2}(145)=$ $1412.69, p<.001, \Delta$ CFI $(0.004), \Delta$ RMSEA $(0.007)]$.

Finally, inspecting the cross-wave paths relevant to the study's hypotheses, it seems associations between different constructs varied across time points. To test this first impression, additional models in the paths relevant for the stress-buffer hypothesis (teacher support and teacher support $\mathrm{x}$ stressful events at wave $\mathrm{X}$ are associated with depressive symptoms at wave $\mathrm{X}+1$ ) were constrained to be the same over different time points and calculated and compared to the unconstrained stress-buffer models. The $\chi^{2}$ difference test did not support the constrained stress-buffer models for boys $\left(\Delta \chi^{2}(12, N=\right.$ $2063)=26.95, p=.008)$ or girls $\left(\Delta \chi^{2}(12, N=2278)=39.37, p<.0001\right)$. Thus, the paths relevant for the stress-buffer hypothesis vary across time for both sexes.

\section{Reference}

Sinharay, S., Stern, H. S., \& Russell, D. (2001). The use of multiple imputation for the analysis of missing data. Psychological Methods, 6, 317-329. doi:10.1037/1082989X.6.4.317 


\section{Supplement D}

Correlations between Age, Supportive Relationships with Teachers, Life-Events, and Depressive Symptoms at each Grade Separated by Sex (above diagonal girls, below diagonal boys)

\begin{tabular}{|c|c|c|c|c|c|c|c|c|c|c|c|c|c|c|c|c|}
\hline & 1 & 2 & 3 & 4 & 5 & 6 & 7 & 8 & 9 & 10 & 11 & 12 & 13 & 14 & 15 & 16 \\
\hline 1. Aget1 & & $.04 *$ & .01 & .05 & -.02 & .00 & -.03 & -.04 & -.04 & .00 & .01 & $.08^{* *}$ & .04 & $.06^{*}$ & .03 & .01 \\
\hline 2. Stresst1 & .03 & & $.40 * *$ & $.33 * *$ & $.28 * *$ & $.26^{* *}$ & $-.26 * *$ & $-.15^{* *}$ & $-.13 * *$ & $-.12 * *$ & $-.10 * *$ & $.42 * *$ & $.29 * *$ & $.25^{* *}$ & $.18 * *$ & $.17 * *$ \\
\hline 3. Stresst 2 & -.01 & $.34 * *$ & & $.48^{* *}$ & $.36^{* *}$ & $.33 * *$ & $-.15 * *$ & $-.21 * *$ & $-.19 * *$ & $-.15 * *$ & $-.12 * *$ & $.26^{* *}$ & $.41 * *$ & $.32 * *$ & $.29 * *$ & $.22 * *$ \\
\hline 4. Stresst3 & -.01 & $.27 * *$ & $.38 * *$ & & $.42 * *$ & $.32 * *$ & $-.14 * *$ & $-.17 * *$ & $-.23 * *$ & $-.13 * *$ & $-.09 * *$ & $.20 * *$ & $.31 * *$ & $.40 * *$ & $.25 * *$ & $.20 * *$ \\
\hline 5. Stresst4 & -.02 & $.22 * *$ & $.25^{* *}$ & $.38 * *$ & & $.41 * *$ & $-.08 * *$ & $-.13 * *$ & $-.15^{* *}$ & $-.16^{* *}$ & $-.13 * *$ & $.15^{* *}$ & $.20 * *$ & $.21 * *$ & $.34 * *$ & $.22 * *$ \\
\hline 6. Stresst5 & -.01 & $.18 * *$ & $.25^{* *}$ & $.32 * *$ & $.34 * *$ & & $-.16 * *$ & $-.13 * *$ & $-.18 * *$ & $-.15^{* *}$ & $-.23 * *$ & $.21 * *$ & $.21 * *$ & $.22 * *$ & $.28 * *$ & $.39 * *$ \\
\hline 7.Supportt1 & .01 & $-.22 * *$ & $-.14 * *$ & $-.12 * *$ & $-.14 * *$ & $-.09 * *$ & & $.56^{* *}$ & $.48 * *$ & $.40 * *$ & $.33 * *$ & $-.37 * *$ & $.28 * *$ & $-.23 * *$ & $-.23 * *$ & $-.17 *$ \\
\hline 8.Supportt2 & .02 & $-.14 * *$ & $-.16 * *$ & $-.16 * *$ & $-.13 * *$ & $-.12 * *$ & $.52 * *$ & & $.61 * *$ & $.51 * *$ & $.45^{* *}$ & $-.22 * *$ & $-.33 * *$ & $-.31 * *$ & $-.28 * *$ & $-.21 *$ \\
\hline 9.Supportt3 & .02 & $-.11 * *$ & $-.09 * *$ & $-.20 * *$ & $-.14 * *$ & $-.08 *$ & $.44 * *$ & $.59 * *$ & & $.62 * *$ & $.55^{* *}$ & $-.23 * *$ & $-.29 * *$ & $-.38 * *$ & $-.32 * *$ & $-.26^{* *}$ \\
\hline 10.Supportt4 & .02 & $-.07 *$ & $-.07 *$ & $-.13 * *$ & $-.13 * *$ & $-.08 *$ & $.38 * *$ & $.47 * *$ & $.54 * *$ & & $.65 * *$ & $-.19 * *$ & $-.23 * *$ & $-.30 * *$ & $-.43 * *$ & $-.30 *=$ \\
\hline 11.Supportt5 & .03 & $-.07 *$ & $-.08 *$ & $-.15 * *$ & $-.14 * *$ & $-.14 * *$ & $.30 * *$ & $.45^{* *}$ & $.49 * *$ & $.56 * *$ & & $-.17 * *$ & $-.20 * *$ & $-.27 * *$ & $-.34 * *$ & $-.38 * *$ \\
\hline 12.Depressiont1 & .02 & $.37 * *$ & $.17 * *$ & $.15^{* *}$ & $.12^{* *}$ & $.08^{*}$ & $-.28 * *$ & $-.18 * *$ & $-.17 * *$ & $-.16^{* *}$ & $-.13 * *$ & & $.48 * *$ & $.39 * *$ & $.33 * *$ & $.27 * *$ \\
\hline 13. Depressiont2 & .04 & $.26^{* *}$ & $.37 * *$ & $.24 * *$ & $.20 * *$ & $.18^{* *}$ & $-.21 * *$ & $-.28 * *$ & $-.23 * *$ & $-.21 * *$ & $-.20 * *$ & $.45^{* *}$ & & $.59 * *$ & $.44 * *$ & $.37 * *$ \\
\hline 14. Depressiont3 & .00 & $.21 * *$ & $.27 * *$ & $.42 * *$ & $.23 * *$ & $.23 * *$ & $-.21 * *$ & $-.25 * *$ & $-.31 * *$ & $-.23 * *$ & $-.24 * *$ & $.35^{* *}$ & $.49 * *$ & & $.56 * *$ & $.51 * *$ \\
\hline 15. Depressiont4 & -.01 & $.16^{* *}$ & $.19 * *$ & $.26^{* *}$ & $.37 * *$ & $.24 * *$ & $-.19 * *$ & $-.23 * *$ & $-.29 * *$ & $-.32 * *$ & $-.25 * *$ & $.29 * *$ & $.40 * *$ & $.52 * *$ & & $.55^{* *}$ \\
\hline 16. Depressiont5 & $.08^{*}$ & $.17 * *$ & $.15^{* *}$ & $.17 * *$ & $.24 * *$ & $.31 * *$ & $-.17 * *$ & $-.22 * *$ & $-.23 * *$ & $-.23 * *$ & $-.30 * *$ & $.29 * *$ & $.37 * *$ & $.42 * *$ & $.53 * *$ & \\
\hline
\end{tabular}

Note. Boys: $N=904$; Girls: $N=1246$; Support = supportive relationships with teachers score; Stress = List of Threatening Experiences 
Questionnaire; Depression = Center for Epidemiological Studies Depression Scale; $\mathrm{t} 1=$ grade $8 ; \mathrm{t} 2=$ grade 9; $\mathrm{t} 3=$ grade $10 ; \mathrm{t} 4=$ grade $11 ; \mathrm{t} 5=$ grade $12 .+p<.10 ; * p<.05 ; * * p<.01 ; * * * p<.001$. 


\section{Supplement E}

Indices of Goodness of Fit and Parsimony of the Tested Models

\begin{tabular}{|c|c|c|c|c|}
\hline Models & $\mathrm{df}$ & $\chi^{2}$ & CFI & RMSEA \\
\hline \multicolumn{5}{|l|}{ Girls } \\
\hline Principle-effect model & 236 & $809.27 * * *$ & 0.981 & 0.033 \\
\hline Reversed Principle-effect model & 236 & $811.34 * * *$ & 0.981 & 0.033 \\
\hline Bidirectional Principle-effect model & 232 & $805.27 * * *$ & 0.981 & 0.033 \\
\hline Stress-Buffer model & 232 & $794.27 * * *$ & 0.982 & 0.033 \\
\hline Reversed Stress-Buffer model & 232 & $803.89 * * *$ & 0.981 & 0.033 \\
\hline Bidirectional Stress-Buffer model & 224 & $783.25 * * *$ & 0.982 & 0.033 \\
\hline Stress-Buffer model-constrained & 244 & $833.64 * * *$ & 0.981 & 0.033 \\
\hline \multicolumn{5}{|l|}{ Boys } \\
\hline Principle-effect model & 236 & $737.05 * * *$ & 0.977 & 0.032 \\
\hline Reversed Principle-effect model & 236 & $734.38 * * *$ & 0.978 & 0.032 \\
\hline Bidirectional Principle-effect model & 232 & $731.45^{* * *}$ & 0.977 & 0.032 \\
\hline Stress-Buffer model & 232 & $712.13 * * *$ & 0.978 & 0.032 \\
\hline Reversed Stress-Buffer model & 232 & $730.31 * * *$ & 0.978 & 0.032 \\
\hline Bidirectional Stress-Buffer model & 224 & $700.82 * * *$ & 0.979 & 0.032 \\
\hline Stress-Buffer model-constrained & 244 & $739.08 * * *$ & 0.978 & 0.031 \\
\hline
\end{tabular}

Note. $\mathrm{CFI}=$ Comparative Fit Index, RMSEA = root mean squared of the residuals. $* p<.05 ; * * p<.01 ; * * * p<.001$. 


\section{Supplement F}

Correlations of all Constructs at the same Wave in the Stress Buffer Models for Girls and Boys.

\begin{tabular}{|c|c|c|}
\hline & Girls & Boys \\
\hline Support intercept - Stress intercept & $-.414 * *$ & $-.498 * *$ \\
\hline Support intercept - Depression intercept & $-.668 * *$ & $-.630 * *$ \\
\hline Support intercept - Stress x Support intercept & $-.417 * *$ & $-.409 * *$ \\
\hline Support intercept - Stress x Depression intercept & $.327 * *$ & $.212 * *$ \\
\hline Stress intercept - Depression intercept & $.645^{* *}$ & $.436 * *$ \\
\hline Stress intercept - Stress x Support intercept & $.977 * *$ & $.995 * *$ \\
\hline Stress intercept - Stress x Depression intercept & $-.908 * *$ & $-.856 * *$ \\
\hline Depression intercept - Stress $\mathrm{x}$ Support intercept & $.702 * *$ & $.397 * *$ \\
\hline Depression intercept - Stress $\mathrm{x}$ Depression intercept & $-.807 * *$ & $-.588 * *$ \\
\hline Stress x Support intercept - Stress x Depression & $-.952 * *$ & $-.885 * *$ \\
\hline intercept & & \\
\hline Supportt1 - Stresst1 & $-.201 * *$ & $-.163 * *$ \\
\hline Supportt1 - Depressiont1 & $-.300 * *$ & $-.201 * *$ \\
\hline Supportt1 - Stress x Supportt1 & $-.192 * *$ & $-.162 * *$ \\
\hline Supportt1 - Stress x Depressiont1 & $.113 * *$ & $.069 *$ \\
\hline Stresst1 - Depressiont1 & $.350 * *$ & $.361 * *$ \\
\hline Stresst1 - Stress x Supportt1 & $.886 * *$ & $.910 * *$ \\
\hline Stresst1 - Stress x Depressiont1 & $-.340 * *$ & $-.234 * *$ \\
\hline Depressiont 1 - Stress x Supportt1 & $.354 * *$ & $.355 * *$ \\
\hline Depressiont 1 - Stress x Depressiont1 & $-.328 * *$ & $-.244 * *$ \\
\hline Stress x Supportt1 - Stress x Depressiont1 & $-.532 * *$ & $-.374 * *$ \\
\hline Supportt2er - Stresst2er & $-.093 * *$ & -.046 \\
\hline Supportt2er - Depressiont2er & $-.156 * *$ & $-.133 * *$ \\
\hline Supportt2er - Stress x Supportt2er & $-.117 * *$ & $-.081 *$ \\
\hline Supportt2er - Stress x Depressiont2er & $.073 *$ & .051 \\
\hline Stresst2er - Depressiont2er & $.264 * *$ & $.300 * *$ \\
\hline Stresst2er - Stress x Supportt2er & $.836 * *$ & $.846^{* *}$ \\
\hline
\end{tabular}


Stresst2er - Stress x Depressiont2er

Depressiont2er - Stress x Supportt2er

Depressiont2er - Stress x Depressiont2er

Stress x Supportt2er - Stress x Depressiont2er

Supportt3er - Stresst3er

Supportt3er - Depressiont3er

Supportt3er - Stress x Supportt3er

Supportt3er - Stress x Depressiont3er

Stresst3er - Depressiont3er

Stresst3er - Stress x Supportt3er

Stresst3er - Stress x Depressiont3er

Depressiont3er - Stress x Supportt3er

Depressiont3er - Stress x Depressiont3er

Stress x Supportt3er - Stress x Depressiont3er

Supportt4er - Stresst4er

Supportt4er - Depressiont4er

Supportt4er - Stress x Supportt4er

Supportt4er - Stress x Depressiont4er

Stresst4er - Depressiont4er

Stresst4er - Stress x Supportt4er

Stresst4er - Stress x Depressiont4er

Depressiont4er - Stress x Supportt4er

Depressiont4er - Stress x Depressiont4er

Stress x Supportt4er - Stress x Depressiont4er

Supportt5er - Stresst5er

Supportt5er - Depressiont5er

Supportt5er - Stress x Supportt5er

Supportt5er - Stress x Depressiont5er

Stresst5er - Depressiont5er

Stresst5er - Stress x Supportt5er

Stresst5er - Stress x Depressiont5er

\begin{tabular}{|c|c|}
\hline$-.370 * *$ & $-.290 * *$ \\
\hline $.255^{* *}$ & $.298 * *$ \\
\hline$-.305^{* *}$ & $-.313^{* *}$ \\
\hline$-.524 * *$ & $-.457 * *$ \\
\hline$-.106^{* *}$ & $-.085^{*}$ \\
\hline$-.158 * *$ & $-.131 * *$ \\
\hline$-.120 * *$ & $-.141 * *$ \\
\hline $.094 * *$ & $.167 * *$ \\
\hline $.226^{* *}$ & $.338^{* *}$ \\
\hline $.846^{* *}$ & $.852 * *$ \\
\hline$-.345^{* *}$ & $-.363 * *$ \\
\hline $.256^{* * *}$ & $.392 * *$ \\
\hline$-.308 * *$ & $-.400 * *$ \\
\hline$-.551 * *$ & $-.569 * *$ \\
\hline-.040 & .011 \\
\hline$-.245^{* *}$ & $-.142 * *$ \\
\hline$-.109 * *$ & -.040 \\
\hline $.125^{* *}$ & .000 \\
\hline $.230 * *$ & $.301 * *$ \\
\hline $.874 * *$ & $.871 * *$ \\
\hline$-.290 * *$ & $-.353 * *$ \\
\hline $.256^{* *}$ & $.289 * *$ \\
\hline$-.263 * *$ & $-.265^{* *}$ \\
\hline$-.527 * *$ & $-.419^{* *}$ \\
\hline$-.160 * *$ & -.046 \\
\hline$-.206 * *$ & $-.146 * *$ \\
\hline$-.189 * *$ & -.049 \\
\hline $.160 * *$ & .075 \\
\hline $.270 * *$ & $.230^{* *}$ \\
\hline $.893 * *$ & $.931 * *$ \\
\hline$-.393 * *$ & $-.329 * *$ \\
\hline
\end{tabular}


Depressiont5er - Stress x Supportt5er

Depressiont5er - Stress x Depressiont5er

Stress x Supportt5er - Stress x Depressiont5er

$\begin{array}{rr}.275 * * & .217 * * \\ -.311 * * & -.133 * * \\ -.568 * * & -.437 * *\end{array}$

Note . Depression = Center for Epidemiological Studies Depression Scale; Stress = List of Threatening Experiences Questionnaire; support = supportive relationships with teachers score $\mathrm{t} 1=$ grade $8 ; \mathrm{t} 2=$ grade $9 ; \mathrm{t} 3=$ grade $10 ; \mathrm{t} 4=$ grade $11 ; \mathrm{t} 5=$ grade $12 ; \mathrm{er}=$ error term. $+p<.02 ; * p<.01 ; * * p<.001$. 